TITLE:

\title{
Work-hardening behaviors of magnesium alloy sheet during in- plane cyclic loading
}

\section{$\operatorname{AUTHOR}(\mathrm{S})$ :}

Hama, Takayuki; Kariyazaki, Yuhta; Hosokawa, Naohiro; Fujimoto, Hitoshi; Takuda, Hirohiko

\section{CITATION:}

Hama, Takayuki ... [et al]. Work-hardening behaviors of magnesium alloy sheet during inplane cyclic loading. Materials Science and Engineering: A 2012, 551: 209-217

\section{ISSUE DATE:}

2012-08

URL:

http://hdl.handle.net/2433/157927

\section{RIGHT:}

(C) 2012 Elsevier B.V.; This is not the published version. Please cite only the published version.; この論文は出版社版でありません。引用の際に は出版社版をご確認ご利用ください。 


\section{Work-Hardening Behaviors of Magnesium Alloy Sheet \\ During In-plane Cyclic Loading}

Takayuki HAMA*

Yuhta KARIYAZAKI

Naohiro HOSOKAWA

Hitoshi FUJIMOTO

Hirohiko TAKUDA

Department of Energy Science and Technology, Kyoto University, Yoshida-honmachi,

Sakyo-ku, Kyoto 606-8501, Japan

Corresponding author: Takayuki HAMA

Department of Energy Science and Technology, Kyoto University

Yoshida-Honmachi, Sakyo-ku, Kyoto 606-8501, Japan

TEL: $\quad+81-(0) 75-753-5418$

FAX: $\quad+81-(0) 75-753-5428$

E-mail: $\quad \underline{\text { hama@energy.kyoto-u.ac.jp }}$ 


\section{Abstract}

This paper presents the work-hardening behaviors of a rolled AZ31B magnesium alloy sheet during in-plane cyclic loading. The overall trend of the stress-strain curve was as follows. As established before, the yield stress under compression was considerably less than that under tension, and an inflected shape was observed in the stress-strain curve during the subsequent tension. Furthermore, an asymmetric evolution of work-hardening was observed as follows. The rate of work-hardening in the late stage of compression became gradually large with an increase in the number of cycles. Owing to this increase in the rate of work-hardening, the stress at the end of compression increased as the number of cycles increased. On the other hand, the rate of work-hardening in the late stage of tension became small as the number of cycles increased, yielding a decrease in the stress at the end of tension with the increase in the number of cycles. The results were almost the same when the cyclic loading test was carried out after tensile strain was applied to the sheet. On the other hand, when the cyclic loading test was carried out after compressive strain was applied, the increase in the rate of work-hardening in the late stage of compression was significantly more pronounced, whereas the inflected shape of the curve during tension was considerably less pronounced. The mechanisms of the above macroscopic behaviors were 
investigated in terms of twinning.

Keywords: magnesium alloy sheet, in-plane cyclic loading, twinning, work-hardening

\section{Introduction}

Magnesium (Mg) alloys are the lightest materials that can be used for structural components. For instance, the density of $\mathrm{Mg}$ is about two-thirds that of aluminum and about one-quarter that of steel. Moreover, $\mathrm{Mg}$ alloys have many advantages, such as high specific strength and stiffness [1], high electromagnetic shielding [1-3], and higher recyclability as compared to plastic $[1,2]$. Because the demand for lightweight materials has been increasing for applications in automobile and electrical devices in order to reduce their environmental impact, $\mathrm{Mg}$ alloys have received much attention. Currently they are applied to various components, such as the housing of laptop computers and cellular phones and automobile body structures.

In general, components made of $\mathrm{Mg}$ alloys are manufactured by die casting and thixoforming [3-5]. Press forming of sheet metal is an efficient process for the development of a wide variety of structural component applications; hence, press forming of $\mathrm{Mg}$ alloy sheets has attracted significant attention, and many studies on the 
press forming of $\mathrm{Mg}$ alloy sheets have been carried out [3-12]. However, the application of press forming to $\mathrm{Mg}$ alloy sheets is still quite preliminary. This is mainly owing to the fact that Mg alloys are hexagonal close-packed (HCP) metals and the mechanical properties of $\mathrm{Mg}$ alloy sheets are crucially different from those of conventional structural sheet metals that have cubic structures, such as steel and aluminum alloy sheets. For instance, the stress-strain curves of rolled $\mathrm{Mg}$ alloy sheets are significantly different at room temperature for uniaxial tension and uniaxial compression [12-14], the stress-strain curve during tension shows a sigmoidal shape when a Mg alloy sheet is subjected to reverse loading from compression to tension $[13,14]$, and a $\mathrm{Mg}$ alloy sheet shows a strong nonlinearity in the stress-strain curve during unloading [14-19] and a strong anisotropic work-hardening behavior in the yield loci [20, 21]. In general, it is understood that the above characteristic deformations arise because of the activation of the direction-dependent $\left\{\begin{array}{llll}1 & 0 & \overline{1} & 2\end{array}\right\}$ deformation twinning. Because a strong basal texture with most of the $c$-axes aligned in the thickness direction is initially formed in the rolled $\mathrm{Mg}$ alloy sheets $[13,22]$, it is difficult for $\left\{\begin{array}{llll}1 & 0 & \overline{1} & 2\end{array}\right\}$ twinning to be activated under in-plane tension, whereas it is easy for it to be activated under in-plane compression. Such asymmetry in the activation of twinning encourages the characteristic deformations in $\mathrm{Mg}$ alloy sheets. 
Because a metal sheet is often subjected to cyclic loading during press forming, for example, during cyclic bending-unbending processes, the cyclic loading behavior is one of the significant deformation characteristics that should be understood. Deformation characteristics of $\mathrm{Mg}$ alloys under multiple cyclic loading processes have been investigated extensively from both macroscopic and microscopic points of view by researchers, with a focus on fatigue properties. A brief survey of the literature is presented. Zhang et al. [23] conducted cyclic tension-compression and torsion tests using an AZ61A extruded tube. In the cyclic tension-compression test, the asymmetry in the stress-strain loop increased with strain amplitude. On the other hand, for the cyclic torsion test, the shear-stress-shear-strain loop showed symmetry regardless of the strain amplitude. They concluded that the cyclic deformation behavior was heavily affected by the loading path and the strain amplitude. Lin and Chen [24] carried out cyclic tension-compression tests using an AZ31B extruded rectangular bar and reported similar results. Park et al. [25] investigated the effect of anisotropy on work-hardening behavior. They conducted a low-cycle fatigue test with various strain amplitudes using an AZ31 bar in the rolling and normal directions and found that the increase in work-hardening during compression was considerably more pronounced when loaded in the normal direction, whereas that during tension was significantly more pronounced 
when loaded in the rolling direction. Wu et al. [26] also conducted a low-cycle fatigue test to investigate the deformation characteristics of a rolled $\mathrm{Mg}$ alloy plate during cyclic loading. They examined the evolution of crystallographic textures during cyclic loading and found that the activation of twinning and detwinning strongly affected the cyclic hardening behavior. Yin et al. [27] carried out an in-situ observation of twinning and detwinning using electron backscatter diffraction during cyclic loading and showed that the twins activated under compression became small or narrow during tension. Sunaga et al. [28] conducted a cyclic bending test on an AZ61 Mg alloy sheet. They found that the intensity ratio of the basal plane decreased with the number of bending cycles owing to the activation of $\left\{\begin{array}{lllll}1 & 0 & \overline{1} & 2\end{array}\right\}$ twinning; however, the ratio remained almost unchanged after the fourth cycle. They also found that the activity of twinning was significant in the vicinity of the compressive side of the bent area, whereas that in the vicinity of the tensile side was negligible. Similar results were reported by the present authors as well [12]. Uota et al. [29] conducted a cyclic bending test on a $\mathrm{Mg}$ alloy sheet, and they observed the microstructure evolution during deformation by conducting electron backscatter diffraction using a scanning electron microscope (SEM-EBSD), and found the following results. Twinning was active under compression. After the loading direction was inverted, detwinning was not active during unloading 
but was active under tension. Other researchers also examined the cyclic deformation behavior of $\mathrm{Mg}$ alloys focusing on the fatigue properties [30, 31]. The above studies clearly suggest that the activities of $\left\{\begin{array}{llll}1 & 0 & 1 & 2\end{array}\right\}$ twinning and detwinning play an important role in macroscopic work-hardening behaviors during cyclic loading.

It should be noted that fatigue properties were the focus of most of the above studies as already mentioned. On the other hand, during press forming, the number of cycles that a sheet would experience is relatively small, but the strains that accordingly arise are generally large. For instance, during the draw-bending process with a draw bead, which was the first phase of "Benchmark 3" of the Numisheet2005 Conference [32], a metal sheet was subjected to several bending-unbending processes, and the maximum equivalent plastic strain that arose was higher than $50 \%$ [33]. Therefore, in order to enhance the application of press forming to $\mathrm{Mg}$ alloy sheets, it is of vital importance to understand the work-hardening behaviors under cyclic loading with relatively high strain amplitudes and small cycle numbers.

Furthermore, it should be noted that the work-hardening behaviors should be examined using the thin $\mathrm{Mg}$ alloy sheets that are usually employed in press forming. However, most of the above studies were carried out using either bars or thick plates $[13,24-27,30,31]$, and a study using thin sheets has been rare. 
This paper is concerned with the work-hardening behaviors under in-plane cyclic tension-compression with relatively high strain amplitudes and small cycle numbers in a rolled $\mathrm{Mg}$ alloy sheet with a thickness of $0.8 \mathrm{~mm}$. Cyclic loading tests were carried out for up to a maximum of ten cycles with strain amplitudes of $2 \%, 4 \%, 6 \%$, and $8 \%$, and stress-strain curves were examined in detail. Further, metallographic observations were carried out after the cyclic loading tests to investigate the effect of twinning and detwinning activities on the work-hardening behaviors.

2. Experimental procedures

\subsection{Material}

The material used in this study was a $0.8 \mathrm{~mm}$ thick commercial rolled AZ31B $\mathrm{Mg}$ alloy sheet $(\mathrm{Mg}-3 \% \mathrm{Al}, 1 \% \mathrm{Zn})$ produced by Osaka Fuji Corporation. Figure 1 shows the geometry of the specimen used in the cyclic loading test. The specimens were machined parallel to the rolling direction and were annealed at $350{ }^{\circ} \mathrm{C}$ for $1.5 \mathrm{~h}$ before the experiments.

2.2 Experimental procedure for in-plane tension-compression test

An in-plane cyclic tension-compression test was carried out. In order to suppress 
buckling during compression, comb-shaped dies were utilized to give compressive forces in the thickness direction of the specimen $[14,34]$. The schematics of the experimental setup and the comb-shaped dies are shown in Fig. 2. The compressive forces in the thickness direction were applied through the elastic forces of four coil springs, each with an elastic modulus of $884 \mathrm{~N} / \mathrm{mm}$. The forces were maintained by screw nuts during the test. The magnitude of the compressive force was $5 \mathrm{kN}$, which was equivalent to about $0.63 \%$ of the $0.2 \%$ proof stress of the material. Mineral hydraulic oil with a nominal kinetic viscosity of $32 \mathrm{cSt}$ at $40{ }^{\circ} \mathrm{C}$ was used as a lubricant to reduce the friction between the comb-shaped dies and the specimen. The effect of friction on the stress-strain curve cannot be completely eliminated [35], but it is still worthwhile examining the qualitative trends in the stress-strain curve.

The experiment was carried out at an initial strain rate of $6.67 \times 10^{-4}$ at room temperature. The strain gauge was used to measure strains in the loading direction during the test. The experimental data were recorded using a data logger approximately every $10 \mathrm{~ms}$. The cyclic loading test was carried out with strain amplitudes of $2 \%, 4 \%$, $6 \%$, and $8 \%$.

Microstructures of the deformed specimens were observed using an optical microscope after the cyclic loading test. A plane perpendicular to the loading direction 
of the deformed specimens was mechanically polished. The samples were then chemically etched by a mixture of $1.05 \mathrm{~g}$ picric acid, $16.45 \mathrm{ml}$ ethanol, $2.5 \mathrm{ml}$ acetic acid, and $2.5 \mathrm{ml}$ distillated water. The area fraction of twins was measured by an image analysis using the free license software Image $\mathrm{J}[36,37]$. The area fraction of twins $R_{t w i n}$ is given in the form

$$
R_{t w i n}=\frac{S_{t w i n}}{S} \times 100
$$

where $S_{\text {twin }}$ is the area of the twins that are present in the observed microstructures and $S$ is the entire area of the observed microstructures.

3. Results and discussion

3.1 Stress-strain curves under monotonic tension and compression

Stress-strain curves obtained by the monotonic tension and compression tests are shown in Fig. 3, and the mechanical properties of the sheet obtained by the monotonic tension test are listed in Table 1. As already reported in the literature [12, 13, 14], a strong asymmetry arises in the curves between tension and compression. The initial yield stress under compression is smaller than that under tension. The usual convex curve arises under tension, whereas a concave curve is exhibited under compression. 
Concerning the work-hardening behaviors under compression, the gradient is low in the early stage of deformation and then becomes large as the compressive strain increases.

\subsection{Stress-strain curves under cyclic loading}

Figure 4 shows the stress-strain curves obtained by the cyclic loading tests with strain amplitudes of $2 \%, 4 \%, 6 \%$, and $8 \%$. All cyclic loading tests started with tension. In the following tests, the deformation from and to a tensile strain of $\alpha / 2 \%$, where $\alpha$ is the strain amplitude, is termed one cycle. In the present experiment, the tests were carried out for up to ten cycles. It should be noted that the sheet fractured at the sixth cycle with a strain amplitude of $8 \%$ (Fig. 4 (d)).

The result with a strain amplitude of $6 \%$ (Fig. 4 (c)) is used to describe the tendency in the stress-strain curve. The stress-strain curve during the first cycle is described as follows. The curve under compression is similar to that under monotonic compression (Fig. 3), and the yield stress during compression is lower than that under tension. After yielding under compression, the stress increases very gently until the end of compression. After the loading direction is inverted from compression to tension, the 
curve during the subsequent tension exhibits a well-known sigmoidal shape, which demonstrates that the stress-strain curves are asymmetrical between the following tension and the compression. In the present paper, the first and second increases in work-hardening during tension are termed the first and second stages of work-hardening, respectively.

The stress-strain curves during the second cycle or later are different from the curve in the first cycle mainly in the following three ways. First, the transition of the curve at yielding under compression is quite sharp during the first cycle, whereas the transition is considerably more gradual during the following cycles.

Second, the rate of work-hardening in the early stage of compression is very similar regardless of the number of cycles, whereas that in the late stage gradually increases as the number of cycles increases. Owing to the increase in the rate of work-hardening, the stress at the end of compression increases with the number of cycles. This tendency can be observed clearly in the changes of stress at the end of compression (Fig. 5 (a)). Similar trends have been reported in the literature [13, 23, 25, $26,31]$.

Third, the rate of work-hardening in the early stage of tension is very similar regardless of the number of cycles, whereas that in the late stage gradually decreases as 
the number of cycles increases. Owing to the decrease in the rate of work-hardening, the stress at the end of tension decreases gradually as the number of cycles increases, as shown in Fig. 5 (b). It is interesting that the stress increases once from the first cycle to the second cycle and then decreases. Similar results were reported in the literature when strain amplitudes were relatively large $[13,25,26]$. Clearly, the tendency in work-hardening during tension is the opposite of that during compression.

On comparing the curve with a strain amplitude of $6 \%$ and the curves with other strain amplitudes, small differences depending on the strain amplitude are found as follows. The amount of increase in the rate of work-hardening in the late stage of compression becomes large as the strain amplitude increases, thereby increasing the stress at the end of compression as the strain amplitude increases (Fig. 5 (a)), and the sigmoidal shape that arises during the subsequent tension is more pronounced as the strain amplitude increases $[23,25,26,31]$. The work-hardening behavior in the late stage of tension is also different depending on the strain amplitude. The tendency that the stress increases once from the first to second cycles and then decreases is not shown when the strain amplitude is small (Fig. 5 (b)). However, the overall qualitative tendencies are clearly similar regardless of the strain amplitude.

In the following section, the focus is on work-hardening behaviors in the late 
stages of compression and tension, and the effect of twinning and detwinning activities on these behaviors is examined in detail using the results obtained for a strain amplitude of $6 \%$.

\subsection{Mechanism of work-hardening behavior during compression}

Let us begin with a re-examination of the work-hardening behavior under monotonic compression. As explained in subsection 3.1, the gradient is low at small strains and then becomes large as the strain increases in the late stage. In general, it is understood from experimental $[13,26,38]$ and numerical $[39,40,41,42]$ investigations that such tendencies arise because the deformation in the early stage is dominated by twinning, whereas in the late stage, twinning is saturated and the slip systems are active.

On the basis of the above mechanism under monotonic compression, the mechanism for the increase in the rate of work-hardening in the late stage of compression with increasing number of cycles during cyclic loading is hypothesized as follows. The rate of work-hardening in the late stage of compression is small when the number of cycles is small because the deformation is still dominated by twinning. As the number of cycles increases, the number of activated twins increases, and accordingly, the deformation mode gradually changes from the twin-dominated mode to 
the slip-dominated mode; thus, the rate of work-hardening increases as the number of cycles increases.

If the above hypothesis is correct, it is expected that the area fraction of twins during compression increases with the number of cycles and then is saturated at a high number of cycles. To confirm this hypothesis, the change in area fraction of twins is examined. Microstructures were observed during the cyclic loading test with a strain amplitude of $6 \%$ at points A, B, C, D, E, F, and A' (Fig. 4 (c)), which correspond to strains of $3 \%, 1.5 \%,-0.75 \%,-3 \%,-1.5 \%, 0.75 \%$, and $3 \%$, respectively, in the first, second, and fifth cycles. It should be noted that point $\mathrm{A}^{\prime}$ in the first cycle is identical to point $\mathrm{A}$ in the second cycle. The initial microstructure (point $\mathrm{O}$ in Fig. 4 (c)) was also observed. For example, the microstructure photographs at points $\mathrm{O}, \mathrm{A}, \mathrm{B}, \mathrm{C}, \mathrm{D}, \mathrm{E}, \mathrm{F}$, and $\mathrm{A}^{\prime}$ in the first cycle are shown in Fig. 6.

Figure 7 (a) shows the change in the area fraction of twins as a function of the number of cycles. The change in area fraction during the first cycle is as follows. The area fraction is initially about $1.5 \%$ (point $\mathrm{O}$ ), and it remains unchanged until the yield point under compression (point B). This result shows that twinning is negligible during the deformation from point $\mathrm{O}$ to point $\mathrm{B}$. Then, the area fraction increases rapidly and reaches approximately $27 \%$ at point $\mathrm{D}$, indicating that twinning is increased during 
compression. The area fraction starts decreasing after the loading direction is inverted to tension at point $\mathrm{D}$. The area fraction decreases constantly from point $\mathrm{D}$ to point $\mathrm{A}^{\prime}$. Clearly, detwinning arises during compression as reported in the literature $[13,26,29$, $31,43]$.

The overall transition is almost independent of the number of cycles. On the other hand, the area fraction increases as the number of cycles increases at most points. This tendency is very clear at point $\mathrm{D}$, which marks the end of compression. This indicates that some twinned regions do not detwin and remain unchanged until the following cycles. A similar tendency was observed in the results reported in the literature [26].

To examine this trend in further detail, the area fraction of twins at point $\mathrm{D}$ is measured at greater cycles (Fig. 7 (b)). The area fraction increases until the fifth cycle, but it remains almost unchanged at the seventh and tenth cycles. Clearly, the area fraction of twins increases as expected, i.e., the number of activated twins increases during compression as the number of cycles increases, and it is then saturated at greater cycles. These results indicate that the deformation at the end of compression is governed primarily by twinning at smaller cycles, while at greater cycles, the deformation mode changes to the slip-dominated mode; thus, the rate of work-hardening increases as the 
number of cycles increases.

3.4 Work-hardening behavior during tension

First, the sigmoidal curve during tension is examined in detail. Figure 8 (a) shows the stress-strain curves obtained under one cyclic loading and five cyclic loadings followed by tension. The strain amplitude during cyclic loading is $6 \%$. During the monotonic tension following cyclic loading, a sigmoidal curve is exhibited, and the second stage of work-hardening arises regardless of the number of cycles in cyclic loading. On the other hand, the second stage of work-hardening begins at a higher strain during the monotonic tension following cyclic loading with five cycles than that during the monotonic tension following cyclic loading with a single cycle. These results indicate that the tensile deformation, which arises before the second stage of work-hardening begins, becomes large as the number of cycles increases.

Considering the cyclic loading test results based on the above results, the reason for the decrease in the rate of work-hardening in the late stage of tension can be explained as follows. The tensile deformation, which occurs before the second stage of work-hardening begins, increases as the number of cycles increases as is seen in Fig. 8 (a); as a result, the apparent work-hardening rate decreases in the late stage of tension as 
the number of cycles increases. Wu et al. [26] also reported a similar result.

The mechanism by which the tensile deformation, which occurs before the second stage of work-hardening begins, increases as the number of cycles increases is hypothesized as follows. The change in the area fraction of twins (Fig. 7 (a)) is examined again with a particular focus on the change during tension (from points $\mathrm{D}$ to $\left.\mathrm{A}^{\prime}\right)$. The area fraction decreases, i.e., detwinning is active, during tension as described in subsection 3.3, and most of the twinned regions are reoriented by detwinning before the loading direction is inverted. This result indicates that the tensile deformation until the second stage of work-hardening begins is primarily dominated by the activity of detwinning, while the activities of twinning and detwinning are less intense after the second stage begins. This hypothesis is supported by the area fractions measured after cyclic loadings followed by tension were applied (Fig. 8 (b)). Points $\mathrm{G}$ and $\mathrm{H}$ are shown in Fig. 8 (a). The area fractions during the last cycle of tension are almost the same as those at point $\mathrm{A}$ of the first cycle, and this trend is independent of the number of cycles performed prior to the last cycle of tension. Similar results were also reported experimentally and numerically in the literature [13, 26, 42, 44]. Because the area fraction that decreases during tension becomes large as the area fraction at the beginning of tension (point $\mathrm{D}$ ) becomes large with the increase in the number of cycles, 
the strain range from the beginning of tension to the beginning of the second stage of work-hardening would also increase, resulting in a decrease in the apparent work-hardening rate in the late stage of tension with the increase in the number of cycles.

\subsection{Discussion}

From the above results, it is hypothesized that the increase in the rate of work-hardening in the late stage of compression may be more pronounced when compressive strain is applied before a cyclic loading test. This is because a certain number of twins is activated during the initial compressive deformation, yielding the change from a twin-dominated mode to a slip-dominated mode earlier than under the original condition.

On the other hand, the work-hardening behaviors may not change largely when tensile strain is applied before a cyclic loading test because the activity of twinning is very small during the initial tensile deformation.

To confirm these hypotheses, the following two experiments were carried out. The first was the cyclic loading test that was carried out after compressive strain was applied. The second was the cyclic loading test that was conducted after tensile strain was applied. 
Figure 9 shows the stress-strain curve obtained with the cyclic loading test after a compressive strain of $-5 \%$ was applied. The strain amplitude was $6 \%$. The rate of work-hardening in the late stage of compression is already large in the first cycle and further increases with the number of cycles. Clearly, the amount of increase in the rate of work-hardening is significantly more pronounced than that in the original result (Fig. 4 (c)), as expected. This result supports our hypothesis. It is further expected that the area fraction at the end of compression would be saturated earlier than in the original result (Fig. 7 (b)). The change in area fraction during this cyclic loading test has not been measured yet, and it will be our future work.

Further, it is interesting that the work-hardening behavior during tension observed in Fig. 9 is also different from that of the original result; the decrease in the rate of work-hardening in the late stage of tension with the increase in the number of cycles is not exhibited. This result may be explained as follows. The amount of compressive strain before the loading direction is inverted to tension was $8 \%$, while the amount of tensile strain before the loading direction is inverted to compression was $6 \%$. Therefore, detwinning is still active at the end of tension, i.e., the second stage of work-hardening has not begun; thus, the decreasing tendency in the rate of work-hardening is not exhibited. 
Figure 10 shows the stress-strain curve obtained with the cyclic loading test after a tensile strain of $4 \%$ was applied. The strain amplitude was $6 \%$. As expected, the overall work-hardening behaviors are almost the same as in the original results (Fig. 4 (c)). This result indicates that the effect of the initial tensile strain on work-hardening during cyclic loading is considerably smaller than that of the initial compressive strain. The above results show that the loading history plays an important role in the work-hardening behavior when a sheet is subjected to in-plane cyclic loading.

\section{Conclusions}

In this study, the work-hardening behavior in a rolled AZ31 Mg alloy sheet was investigated under in-plane cyclic tension-compression with relatively high strain amplitudes and small numbers of cycles with a focus on the effect of twinning and detwinning activities. The results obtained in this study are summarized below.

1. The stress-strain curves are asymmetrical between tension and compression. The rate of work-hardening in the late stage of compression gradually increases with an increase in the number of cycles. On the other hand, the rate of work-hardening in the late stage of tension gradually decreases, i.e., the tensile deformation, which 
occurs before the second stage of work-hardening begins, increases as the number of cycles increases. The change in the rate of work-hardening in the late stage of compression is more pronounced with an increase in the strain amplitude.

2. The mechanism by which the rate of work-hardening in the late stage of compression increases with the number of cycles is hypothesized to be as follows. The deformation in the late stage of compression is dominated by twinning when the number of cycles is small; hence, the rate of work-hardening is small. Because the deformation mode gradually changes from the twin-dominated mode to the slip-dominated mode as the number of cycles increases, the rate of work-hardening also increases. This hypothesis is supported by the evolution of the area fraction of twins with the number of cycles.

3. The mechanism by which the rate of work-hardening in the late stage of tension gradually decreases as the number of cycles increases is hypothesized to be as follows. The tensile deformation until the second rapid increase in work-hardening occurs is dominated by the activity of detwinning. Because the area fraction that decreases during tension becomes large as the area fraction at the beginning of tension becomes large with the increase in the number of cycles, the strain range from the beginning of tension to the beginning of the second rapid increase in 
work-hardening would also increase, resulting in a decrease in the apparent work-hardening rate in the late stage of tension with the increase in the number of cycles. This hypothesis is also supported by the evolution of the area fraction of twins with the number of cycles.

4. As expected from the above results, the work-hardening behaviors change significantly when the initial compressive strain is applied before a cyclic loading test, whereas they remain almost unchanged when the initial tensile strain is applied. These results indicate that the loading history plays an important role in the work-hardening behaviors when a sheet is subjected to in-plane cyclic loading.

Acknowledgements

This work was partially supported by KAKENHI (23760697: Grant-in-Aid for Young Scientist (B)) in Japan and the Amada Foundation for metal work technology.

\section{References}

[1] B.L. Mordike, T. Ebert, Materials Science and Engineering A 302 (2001), 37-45.

[2] Y. Chino, T. Furuta, M. Hakamada, M. Mabuchi, Journal of Materials Research 41 (2006), 3229-3232. 
[3] H.J. Kim, S.C. Choi, K.T. Lee, H.Y. Kim, Materials Transactions 49 (2008), 1112-1119.

[4] J. Kaneko, M. Sugamata, Journal of Japan Institute of Light Metals 54 (2004), 484-492 (in Japanese).

[5] Y.S. Lee, M.C. Kim, S.W. Kim, Y.N. Kwon, S.W. Choi, J.H. Lee, Journal of Materials Processing Technology 187-188 (2007), 103-107.

[6] E. Doege, K. Droder, Journal of Materials Processing Technology 115 (2001), 14-19.

[7] F.K. Chen, T.B. Huang, C.K. Chang, International Journal of Machine Tools \& Manufacture 43 (2003), 1553-1559.

[8] M.H. Lee, H.Y. Kim, H.K. Kim, G.D. Kim, S.I. Oh, Materials Transactions, 49 (2008), 1120-1123.

[9] S. Yi, J. Bohlen, F. Heinemann, D. Letzig, Acta Materialia, 58 (2010), 592-605.

[10] L. Zhang, G. Huang, H. Zhang, B. Song, Journal of Materials Processing Technology, 211 (2011), 644-649.

[11] S.M. Lee, C.G. Kang, S.B. Kang, International Journal of Advanced Manufacturing Technology, 51 (2010), 891-903.

[12] T. Hama, Y. Kariyazaki, K. Ochi, H. Fujimoto, H. Takuda, Materials Transactions 
51 (2010), 685-693.

[13] X.Y. Lou, M. Li, R.K. Boger, S.R. Agnew, R.H. Wagoner, International Journal of Plasticity 23 (2007), 44-86.

[14] T. Hama, K. Ochi, N. Kitamura, H. Fujimoto, H. Takuda, Steel Research International, Special Edition (2011), 1054-1059.

[15] T. Hama, H. Takuda, International Journal of Plasticity, 27(2011), 1072-1092.

[16] C.H. Cáceres, T. Sumitomo, M. Veidt, Acta Materialia 51 (2003), 6211-6218.

[17] G.E. Mann, T. Sumitomo, C.H. Cáceres, J.R. Griffiths, Materials Science and Engineering A 456 (2007), 138-146.

[18] Y. Li M. Enoki, Materials Transactions 49 (2008), 1800-1805.

[19] O. Muránsky, D.G. Carr, P. Sittner, E.C. Oliver, International Journal of Plasticity 25 (2009), 1107-1127.

[20] M. Andar, D. Steglich, T. Kuwabara, in: F. Chinesta, Y. Chastel, M. Mansori (Eds.), International Conference on Advances in Materials and Processing Technologies, American Institute of Physics, 2010, pp. 75-80.

[21] T. Hama, and H. Takuda, Computational Materials Science, 51 (2012), 156-164.

[22] Y. Chino, J.S. Lee, K. Sassa, A. Kamiya, M. Mabuchi, Materials Letters 60 (2006), 173-176. 
[23] J. Zhang, Q. Yu, Y. Jiang, Q. Li, International Journal of Plasticity 27 (2011), 768-787.

[24] X.Z. Lin, D.L. Chen, Materials Science and Engineering A 496 (2008), 106-113.

[25] S.H. Park, S. Hong, W. Bang, C.S. Lee, Materials Science and Engineering A 527 (2010), 417-423.

[26] L. Wu, S.R. Agnew, T. Ren, D.W. Brown, B. Clausen, G.M. Stoica, H.R. Wenk, P.K. Liaw, AZ31B, Materials Science and Engineering A 527 (2010), 7057-7067.

[27] S.M. Yin, H.J. Yang, S.X. Li, S.D. Wu, F. Yang, Scripta Materialia 58 (2008), 751-754.

[28] Y. Sunaga, Y. Tanaka, M. Asakawa, M. Katoh, M. Kobayashi, Journal of Japan Institute of Light Metals, 59 (2009), 655-658. (in Japanese)

[29] T. Uota, T. Suzu, S. Fukumoto, A. Yamamoto, Materials Transactions 50 (2009), $2118-2120$

[30] M. Matsuzuki, S. Horibe, Materials Science and Engineering A 504 (2009), 169-174.

[31] C. Guillemer, M. Clavel, G. Cailletaud, International Journal of Plasticity 27 (2011), 2068-2084.

[32] T. Stoughton, D. Green, M. Iadicola, in: J. Cao, M.F. Shi, T.B. Stoughton, C.T. 
Wang, L. Zhang (Eds.), Proceedings of Numisheet’ 05 6th International Conference and Workshop on Numerical Simulation of 3D Sheet Forming Processes: On the Cutting Edge of Technology, Part B, Amer Inst Physics 778, Melville, pp. 11571172, 2005.

[33] M.C. Oliveira, J.L. Alves, B.M Chaparro, and L.F. Menezes, International Journal of Plasticity 23 (2007), 516-543.

[34] T. Kuwabara, Y. Kumano, J. Ziegelheim, L. Kurosaki, International Journal of Plasticity 25 (2009), 1759-1776.

[35] R.K. Boger, R.H. Wagoner, F. Barlat, M.G. Lee, K. Chung, International Journal of Plasticity, 21 (2005), 2319-2343.

[36] Y. Chino, K. Kimura, M. Hakamada, M. Mabuchi, Materials Science and Engineering A 485 (2008), 311-317.

[37] Y. Chino, K. Kimura, M. Mabuchi, Materials Science and Engineering A 486 (2008), 481-488.

[38] D.W. Brown, S.R. Agnew, M.A.M. Bourke, T.M. Holden, S.C. Vogel, C.N. Tomé, Materials Science and Engineering A 399 (2005), 1-12.

[39] H. Wang, B. Raeisinia, P.D. Wu, S.R. Agnew, C.N. Tomé, International Journal of Solids and Structures, 47 (2010), 2905-2917. 
[40] S.B. Yi, C.H.J. Davies, H.-G. Brokmeier, R.E. Bolmaro, K.U. Kainer, J. Homeyer, Acta Materialia 54 (2006), 549-562.

[41] S.H. Choi, E.J. Shin, B.S. Seong, Acta Materialia 55 (2007), 4181-4192.

[42] G. Proust, C.N. Tomé, A. Jain, S.R. Agnew, International Journal of Plasticity 25 (2008), 861-880.

[43] Y.N. Wang, J.C. Huang, Acta Materialia 55 (2007), 897-905.

[44] T. Hama, H. Takuda, Steel Research International, in press. 
Figure and table captions

Fig. 1 Geometry of specimen used in cyclic loading test.

Fig. 2 Schematics of experimental apparatus for cyclic loading test.

(a) Experimental setup.

(b) Comb-shaped dies.

Fig. 3 Stress-strain curves obtained by monotonic tension and compression tests.

Fig. 4 Stress-strain curves obtained by cyclic loading tests with strain amplitudes of $2 \%, 4 \%, 6 \%$, and $8 \%$.
(a) Strain amplitude of $2 \%$.
(b) Strain amplitude of $4 \%$.
(c) Strain amplitude of $6 \%$.
(d) Strain amplitude of $8 \%$.

Fig. 5 Changes in stress at the end of tension and compression.

(a) Stress at the end of compression with strain amplitudes of $2 \%, 4 \%, 6 \%$, and $8 \%$.

(b) Stress at the end of tension with strain amplitudes of $2 \%, 4 \%, 6 \%$, and $8 \%$.

Fig. 6 Photographs of microstructure at points $\mathrm{O}, \mathrm{A}, \mathrm{B}, \mathrm{C}, \mathrm{D}, \mathrm{E}, \mathrm{F}$, and $\mathrm{A}^{\prime}$ in the first cycle (for a strain amplitude of $6 \%$ ). 

(a) Point O.
(b) Point A.
(c) Point B.
(d) Point C.
(e) Point D.
(f) Point E.
(g) Point F.
(h) Point A'.

Fig. 7 Changes in area fraction of twins.

(a) Area fraction of twins at all observed points during cycles 1, 2, and 5.

(b) Change in area fraction of twins at point $\mathrm{D}$ as a function of the number of cycles.

Fig. 8 Results obtained by one and five cyclic loadings followed by tension.
(a) Stress-strain curves.
(b) Area fraction of twins.

Fig. 9 Stress-strain curve obtained by cyclic loading tests after compressive strains were applied with a strain amplitude of $6 \%$.

Fig. 10 Stress-strain curve obtained by cyclic loading test after tensile strain was applied with a strain amplitude of $6 \%$. 


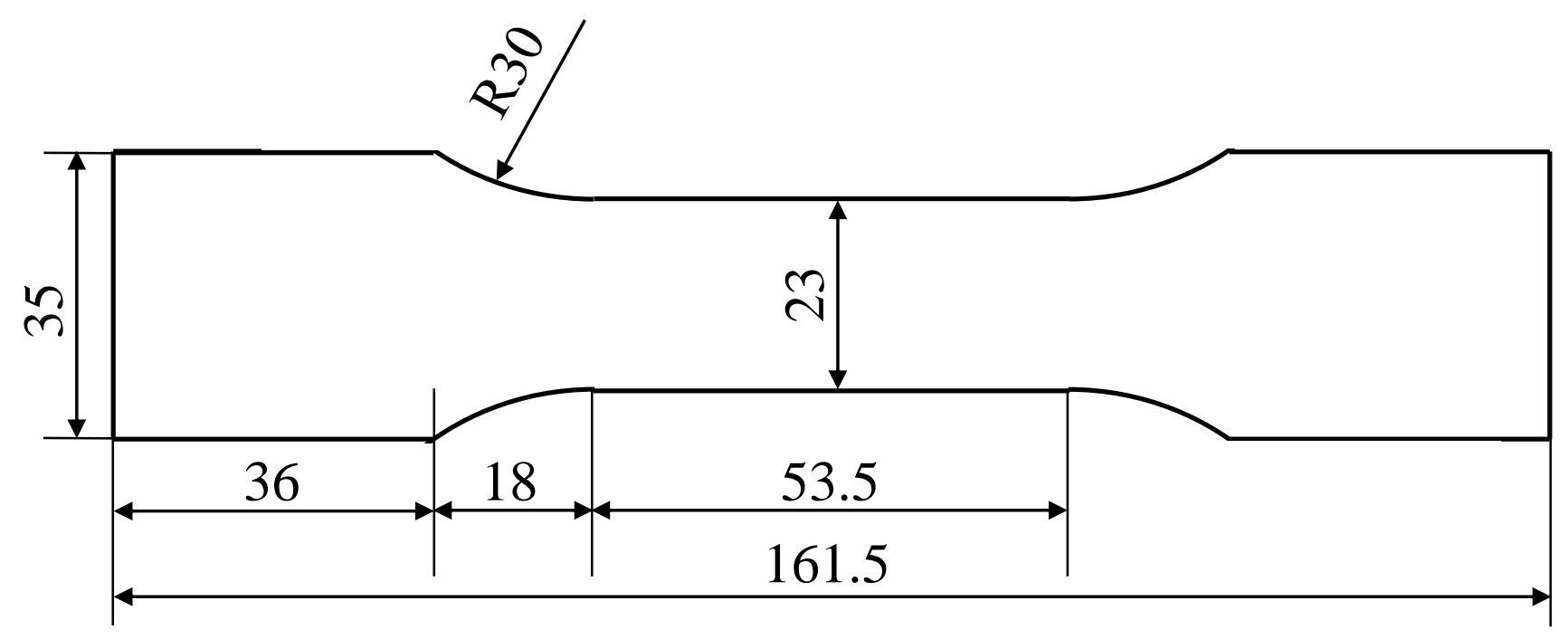

Fig. 1 Geometry of specimen used in cyclic loading test. 


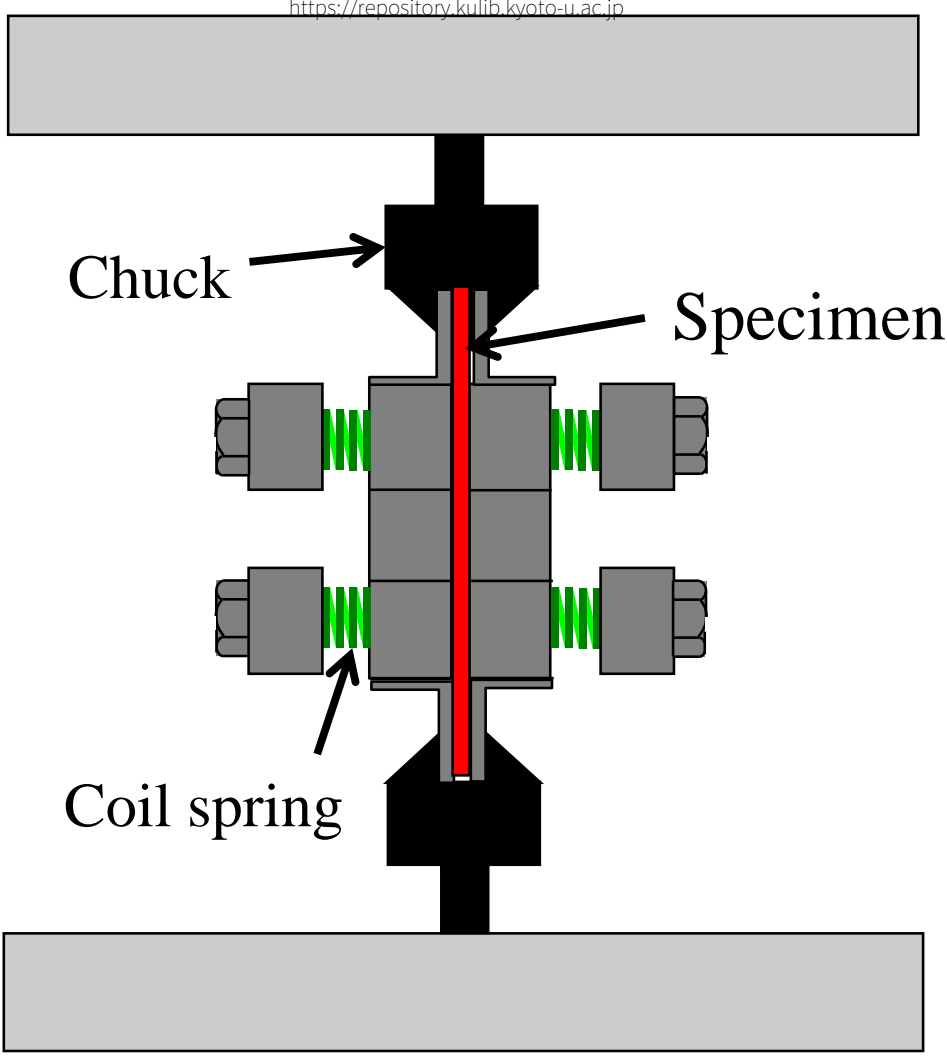

(a) Experimental setup.

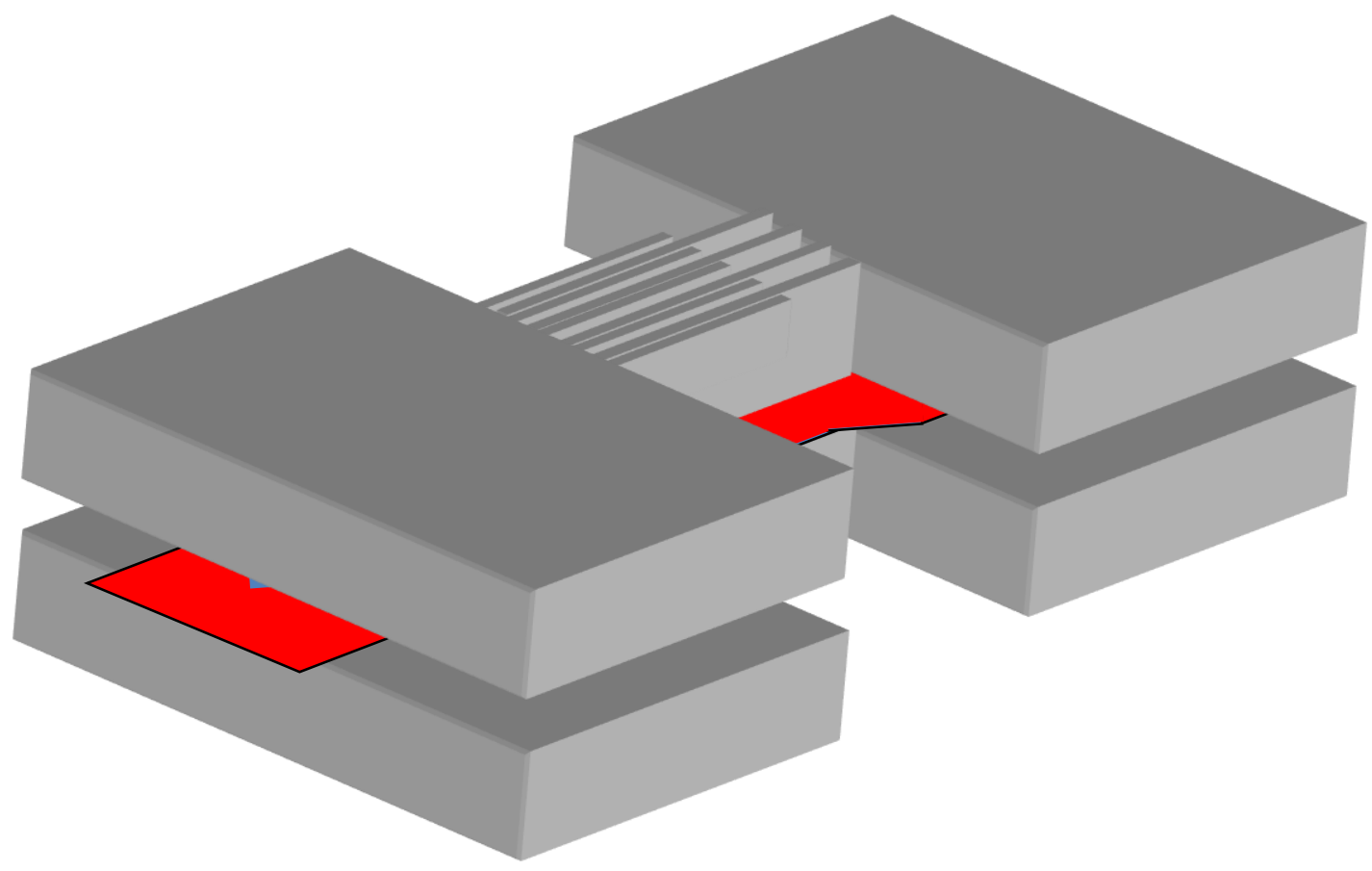

(b) Comb-shaped dies.

Fig. 2 Schematics of experimental apparatus for cyclic loading test. 


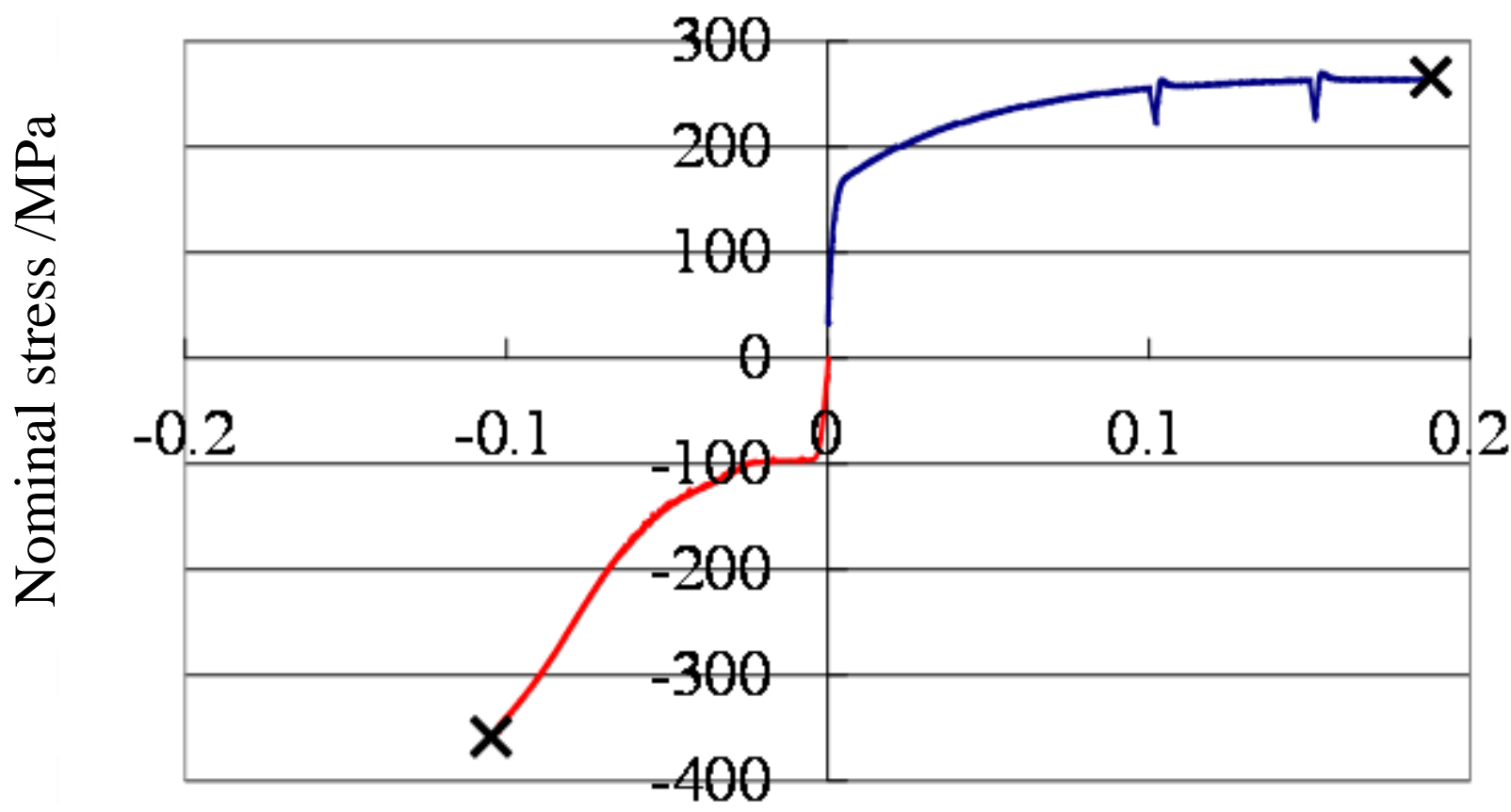

Nominal strain

Fig. 3 Stress- strain curves obtained by monotonic tension and compression tests. 


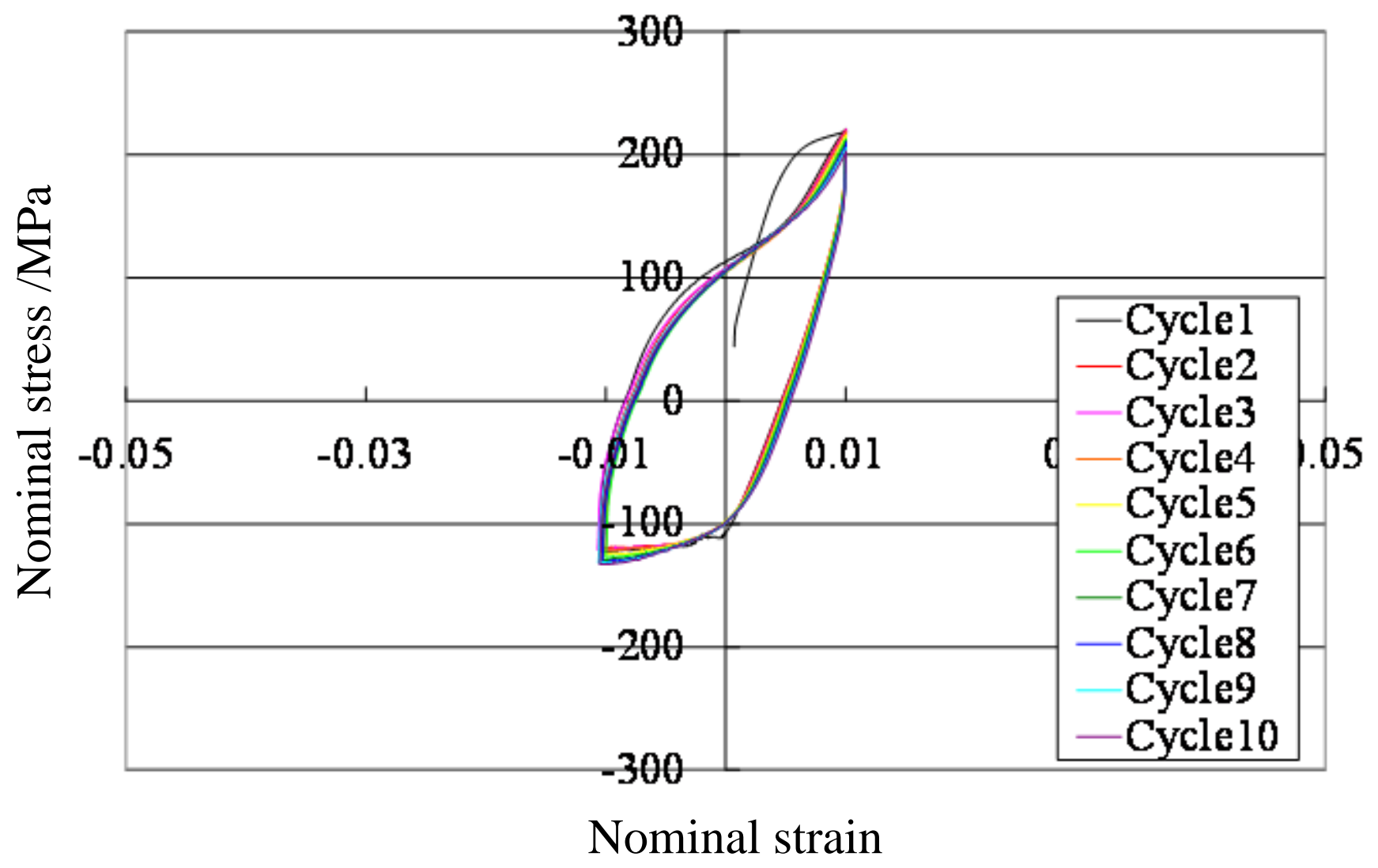

(a) Strain amplitude of $2 \%$. 


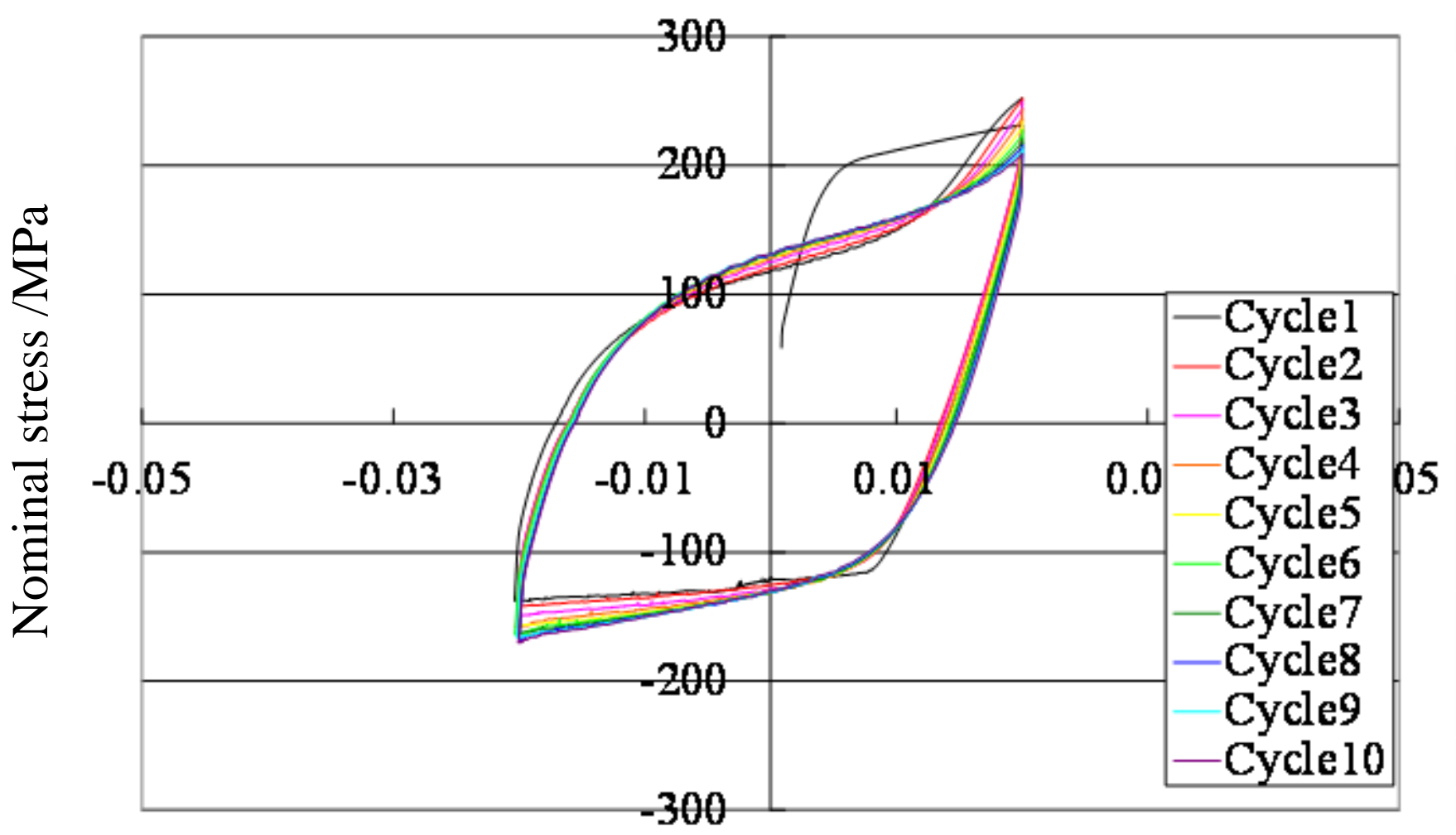

Nominal strain

(b) Strain amplitude of $4 \%$. 


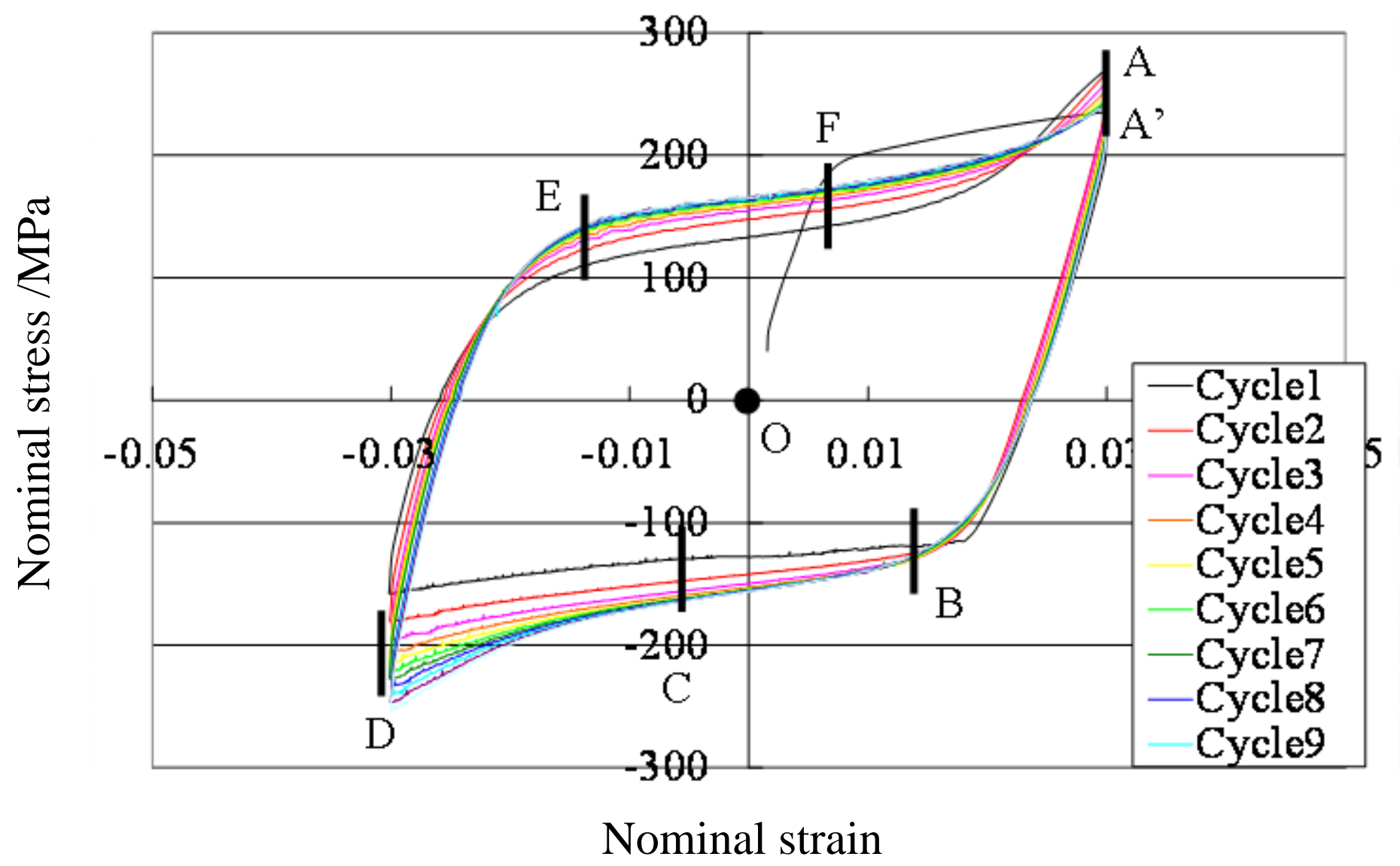

(c) Strain amplitude of $6 \%$. 


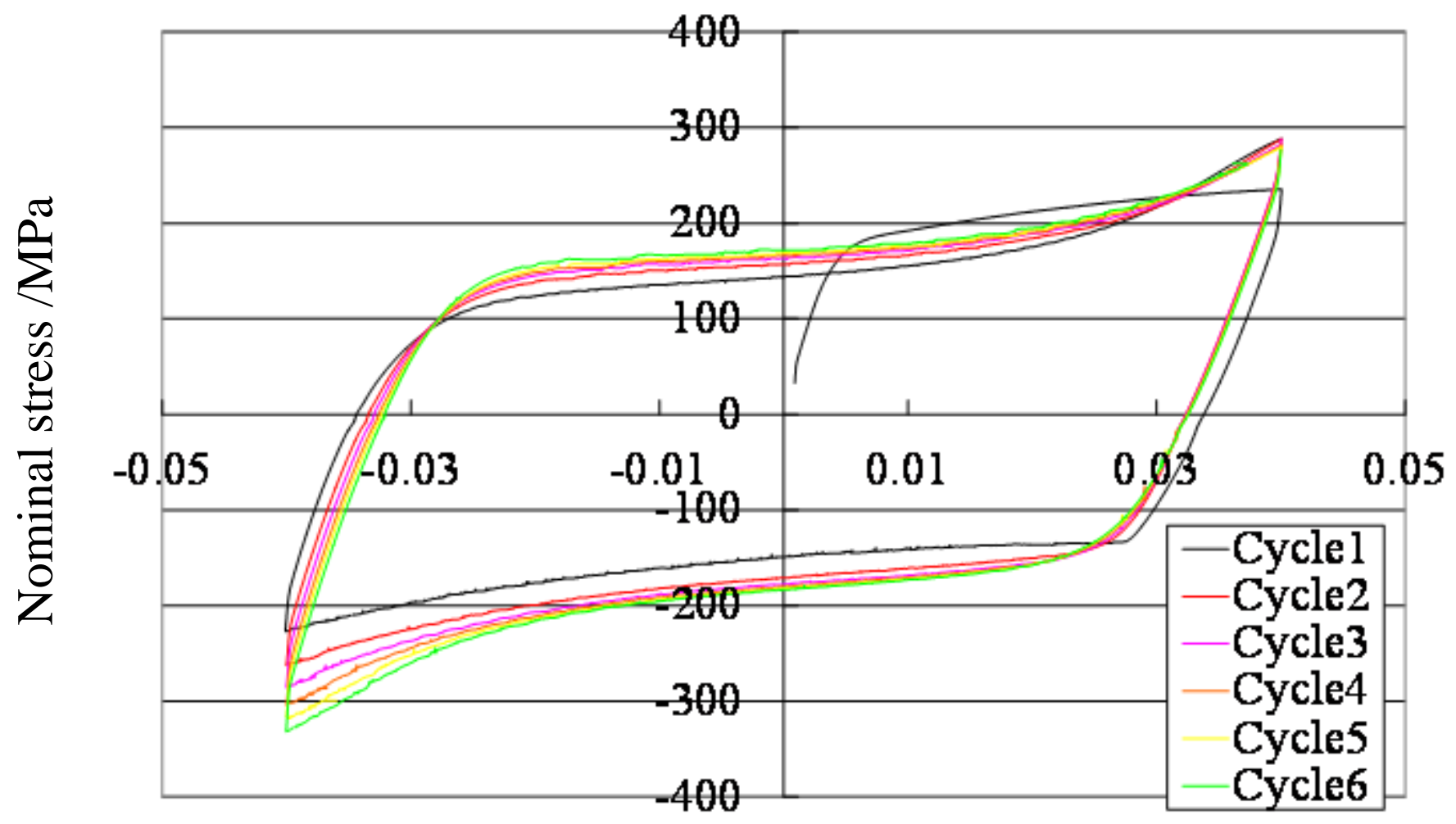

Nominal strain

(d) Strain amplitude of $8 \%$.

Fig. 4 Stress-strain curves obtained by cyclic loading tests with strain amplitudes of $2 \%, 4 \%, 6 \%$, and $8 \%$. 


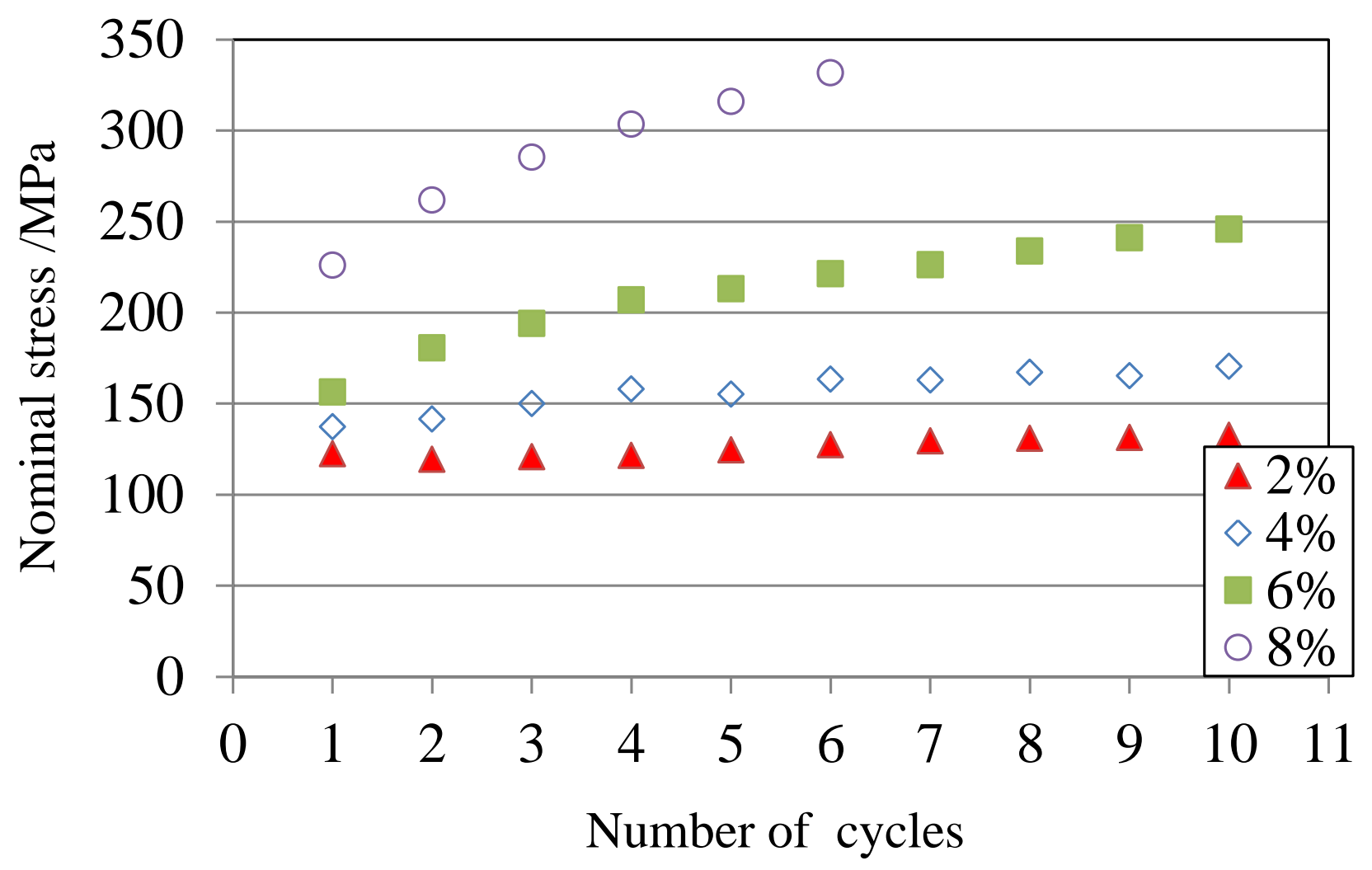

(a) Stress at the end of compression with strain amplitudes of $2 \%, 4 \%, 6 \%$, and $8 \%$. 


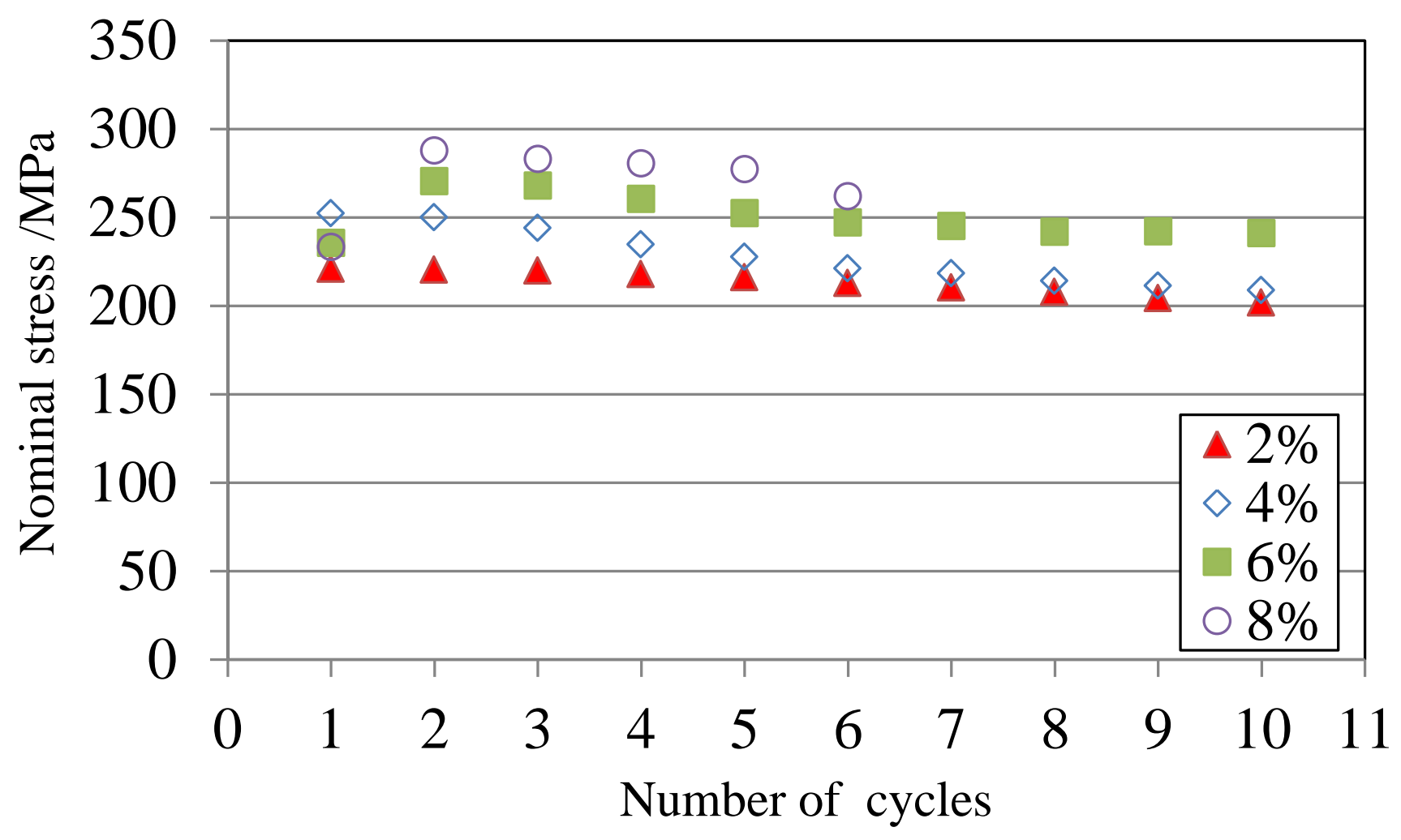

(b) Stress at the end of tension

with strain amplitudes of $2 \%, 4 \%, 6 \%$, and $8 \%$.

Fig.5 Changes in stress at the end of tension and compression. 


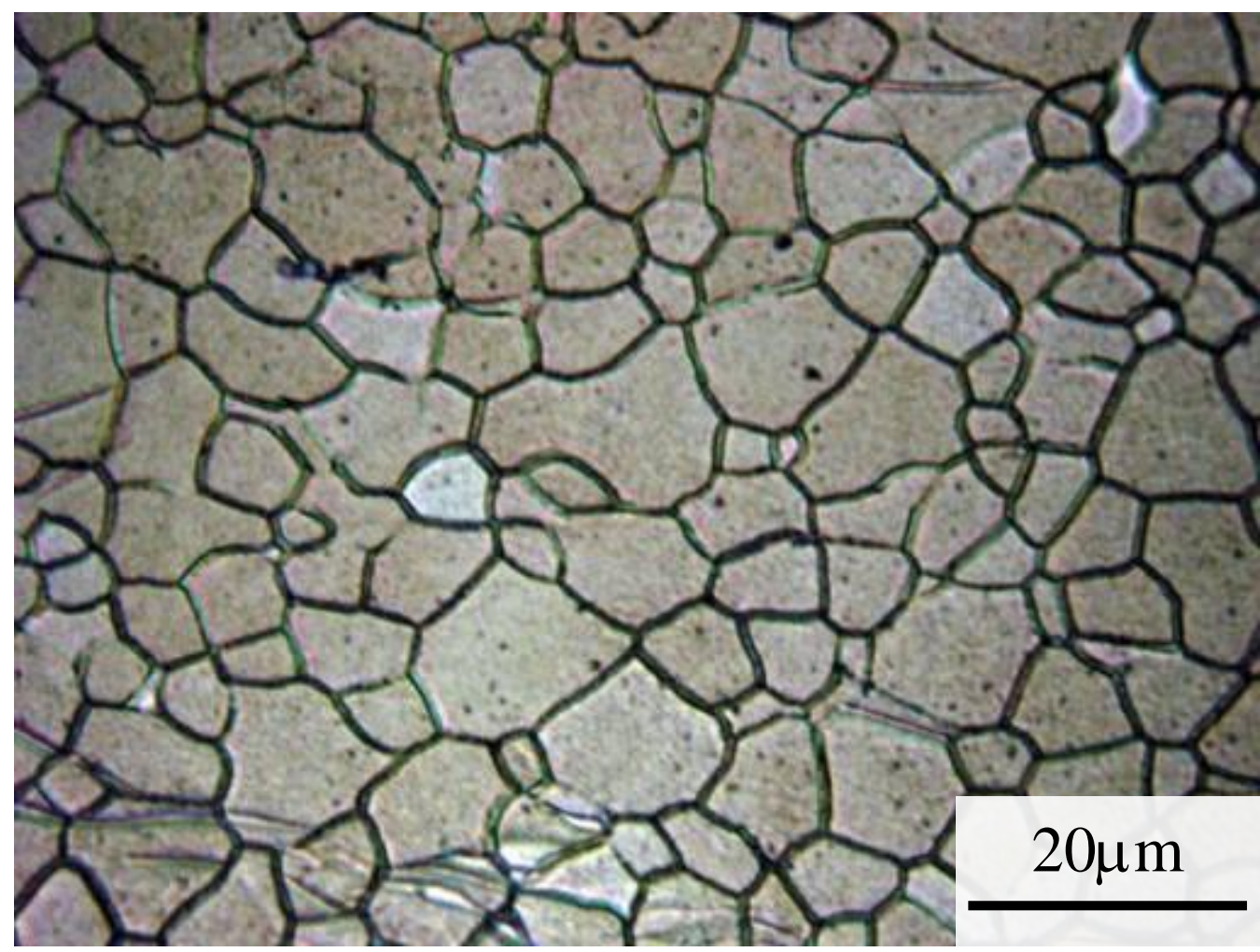

(a) Point O.

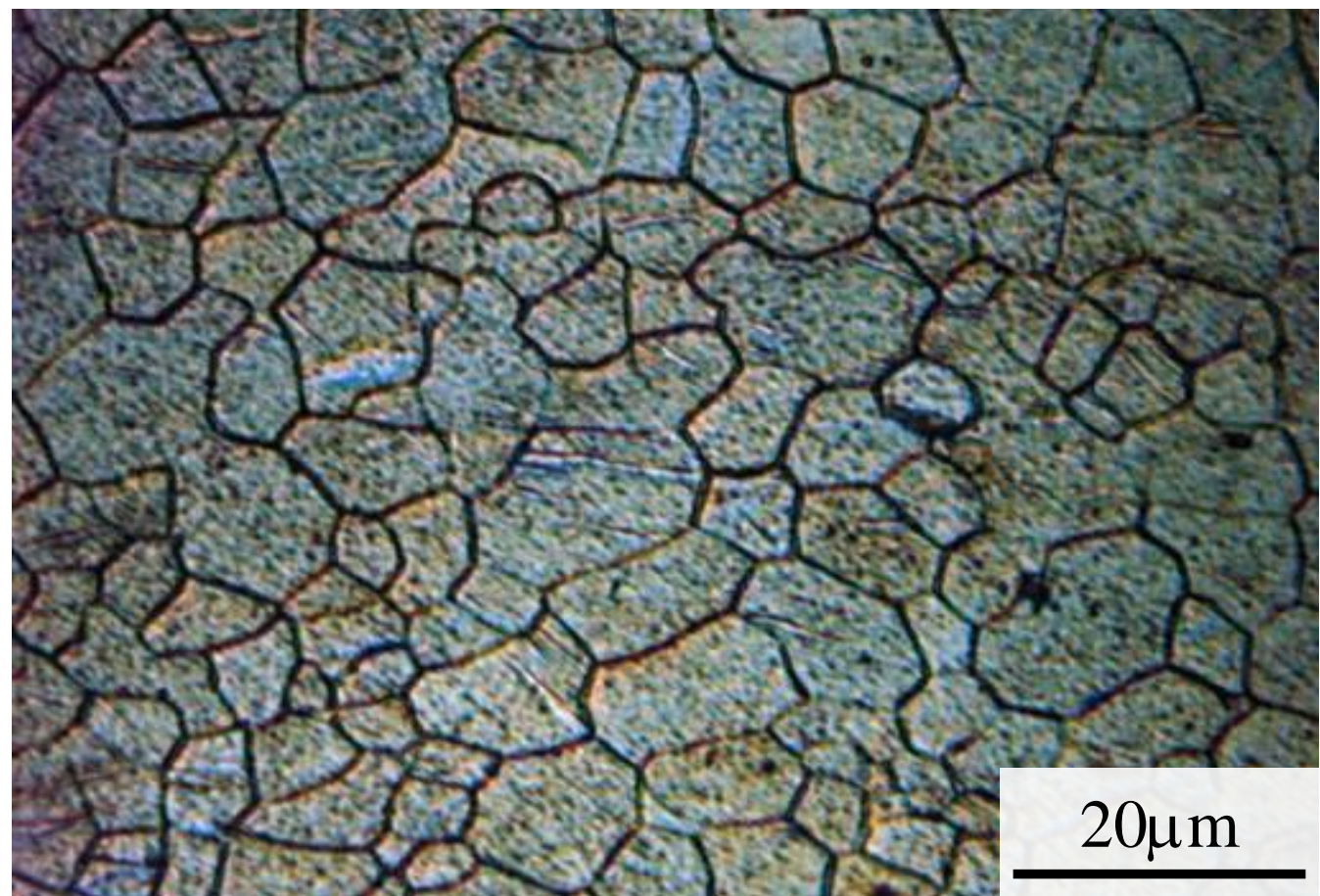

(b) Point A. 


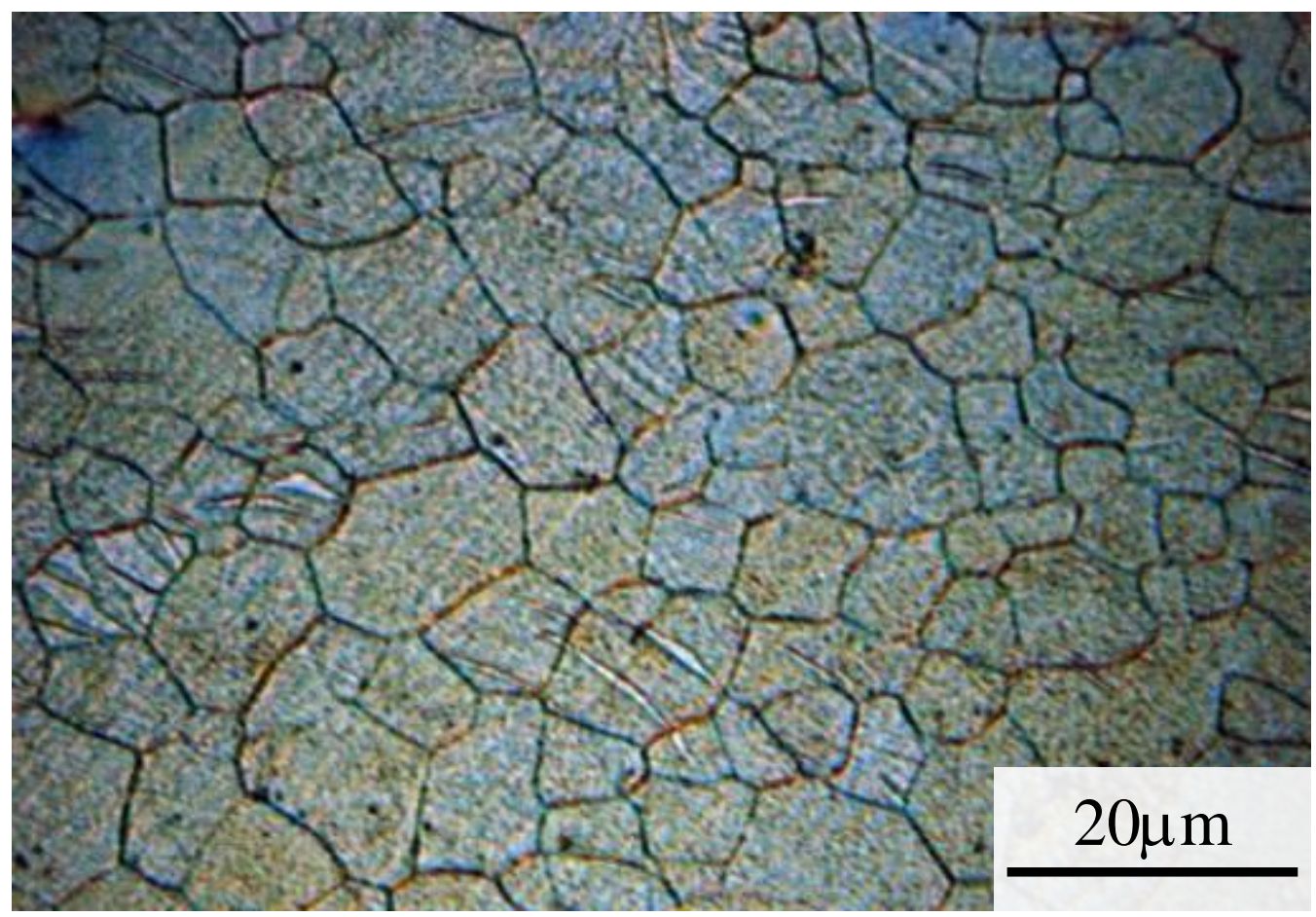

\section{(c) Point B.}

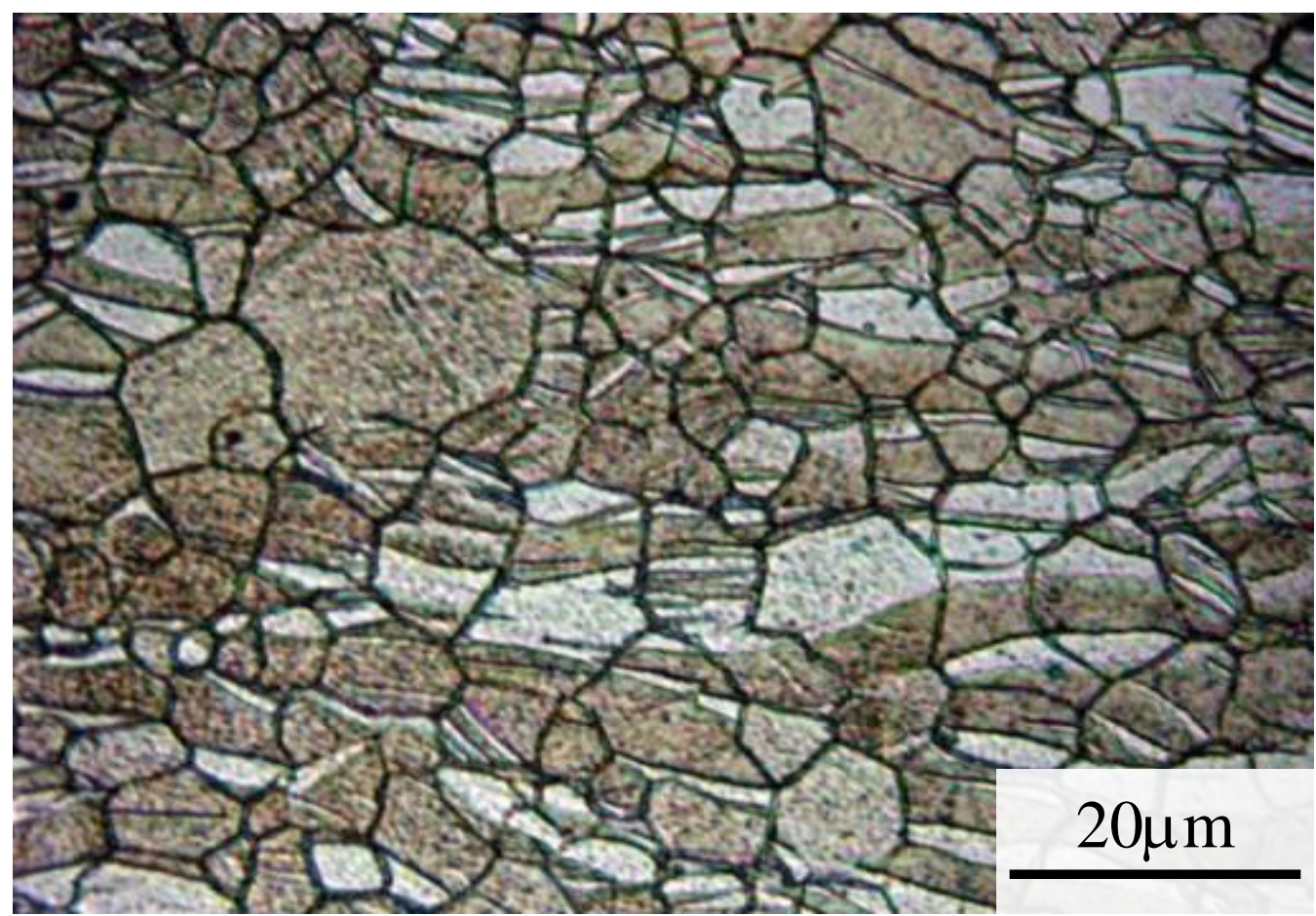

\section{(d) Point C.}




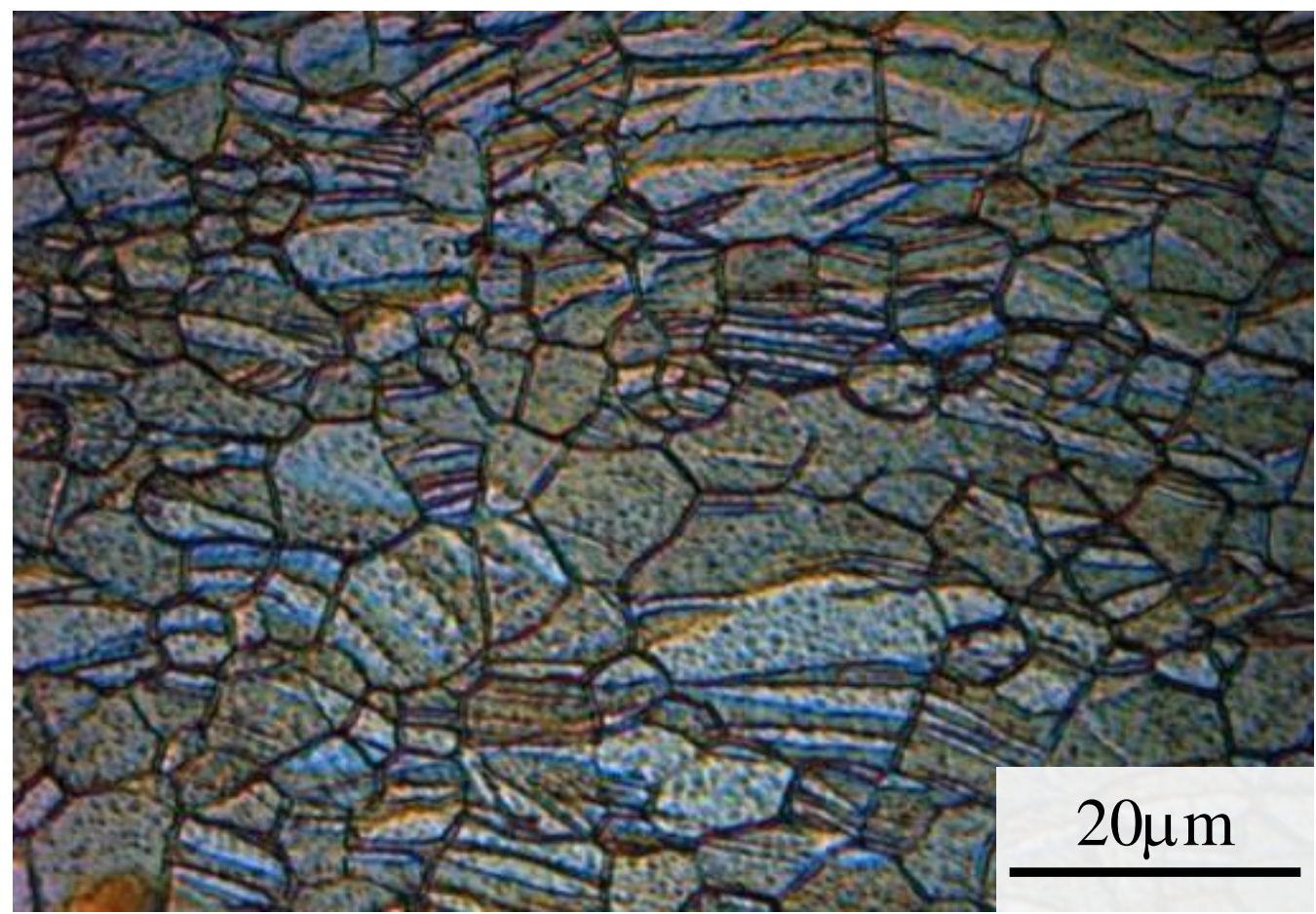

(e) Point D.

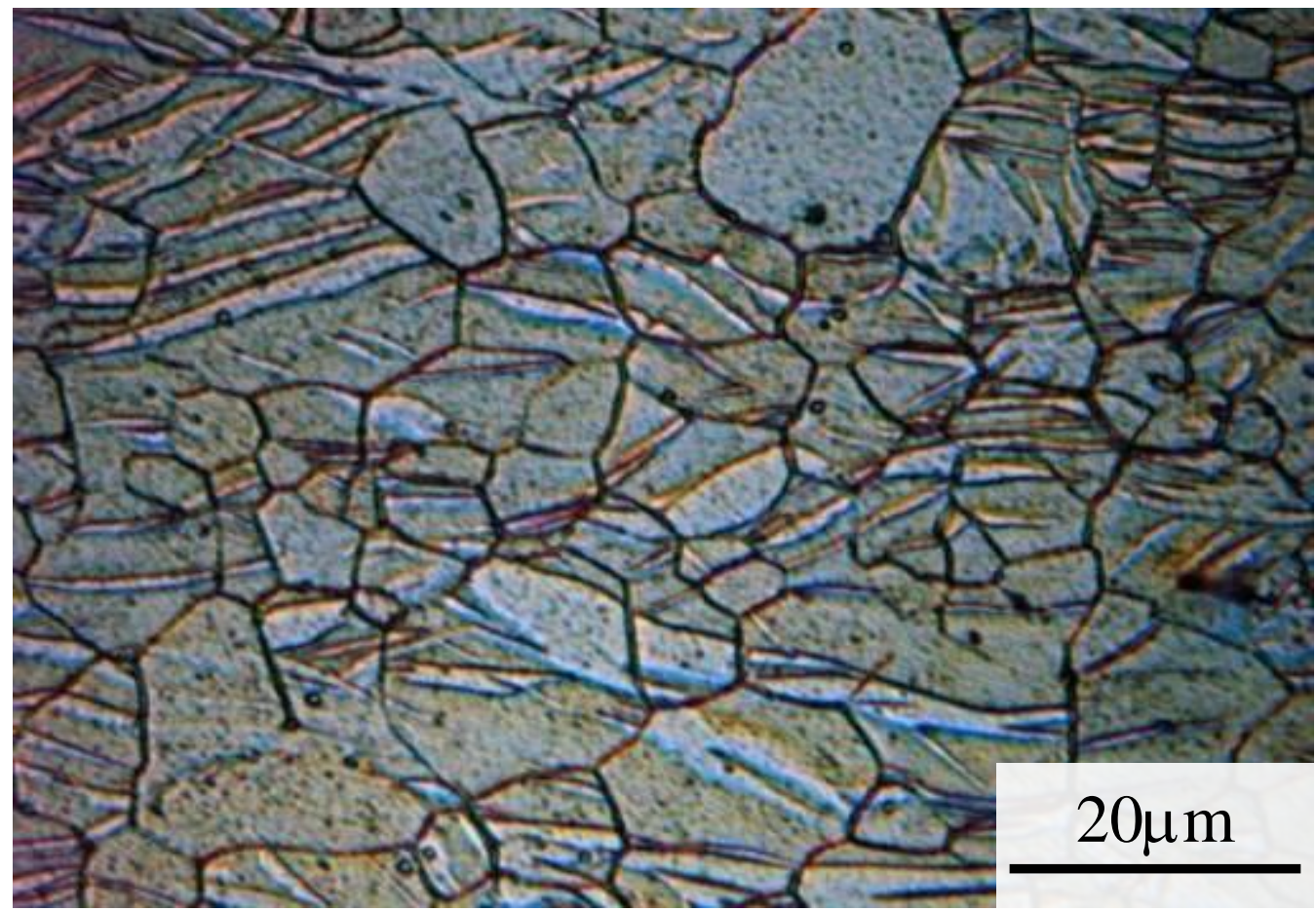

(f) Point E. 


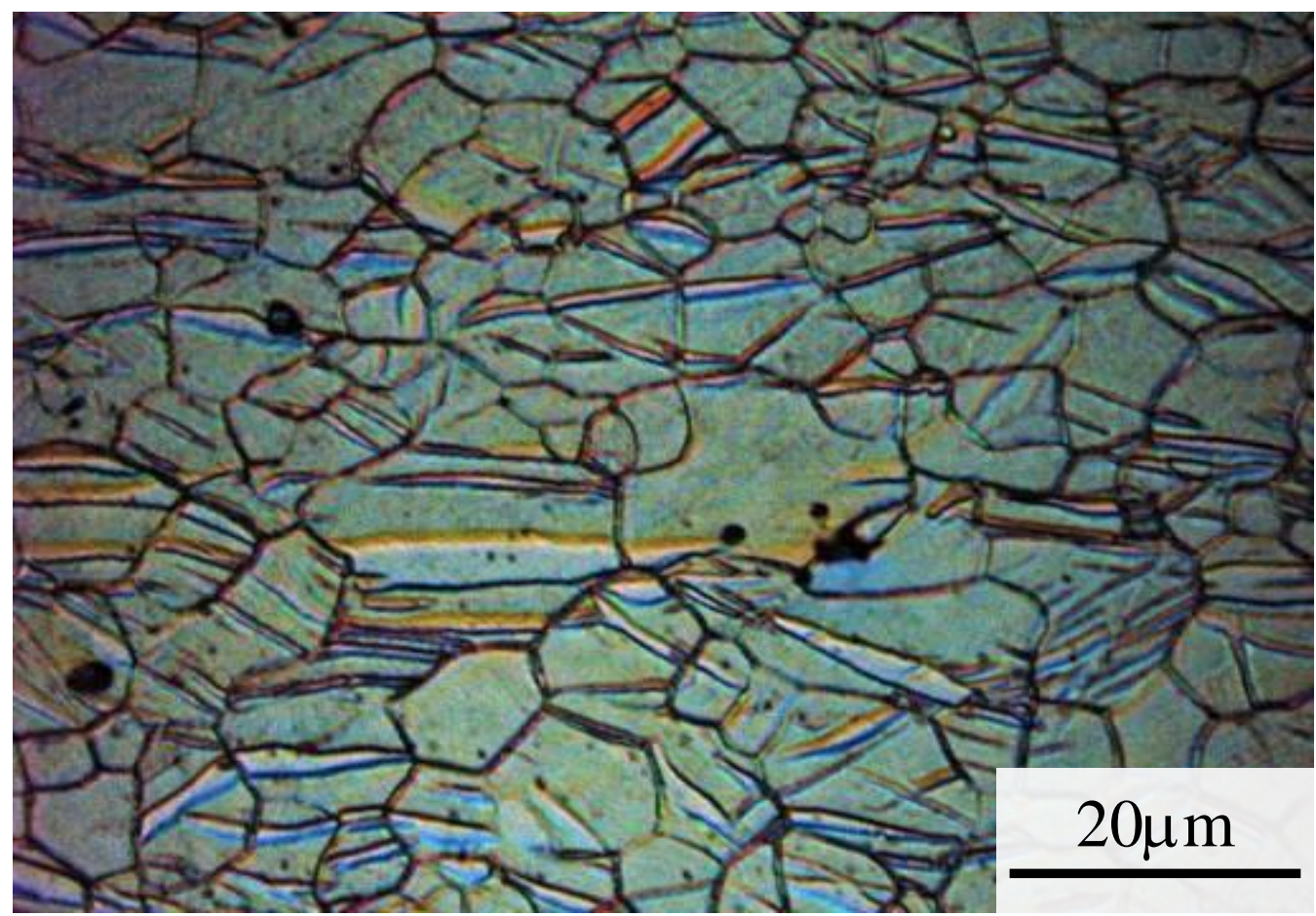

(g) Point F.

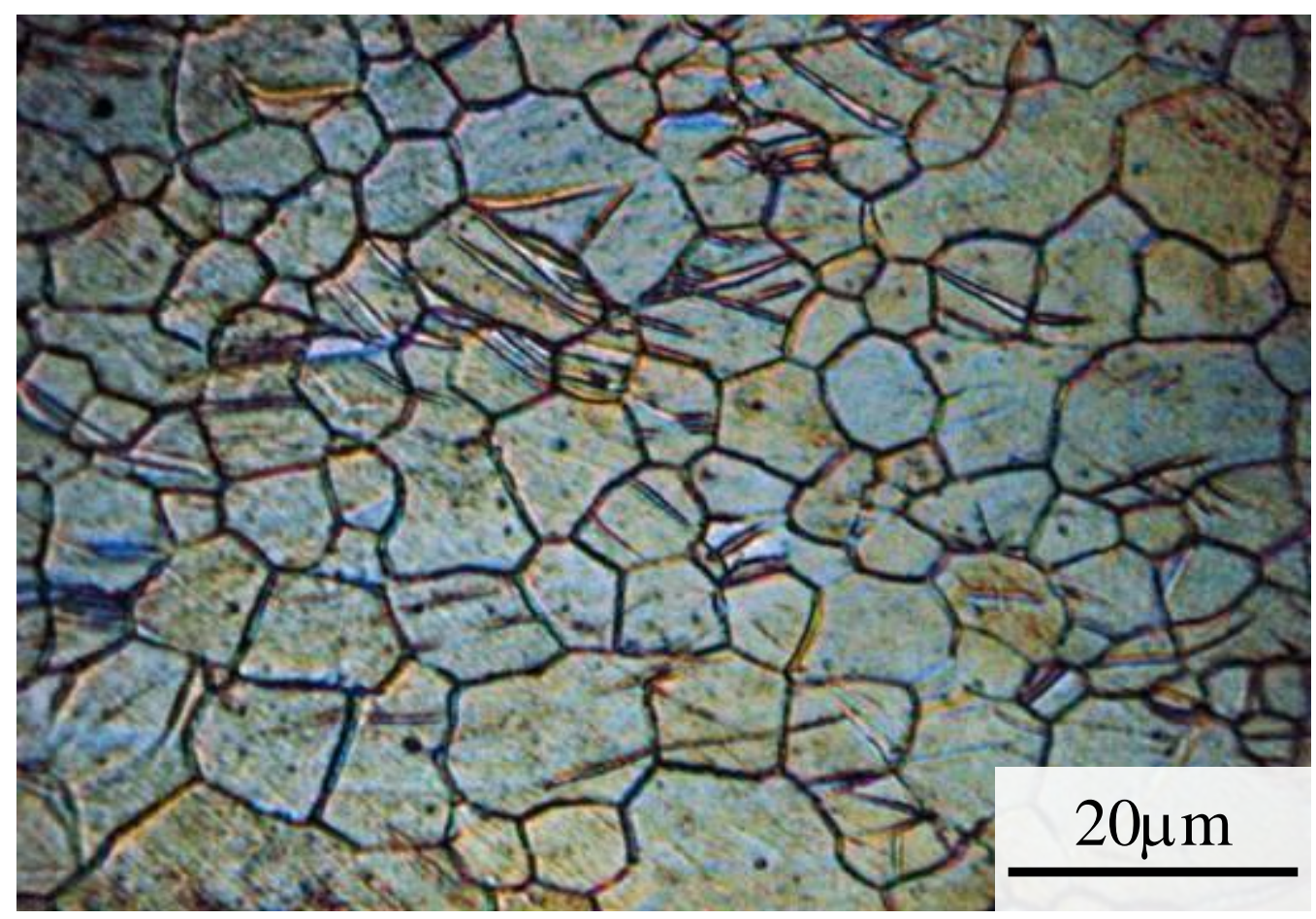

(h) Point $A^{\prime}$.

Fig. 6 Photographs of microstructure at points O, A, B, C, D, E, F, and $\mathrm{A}^{\prime}$ in the first cycle (for a strain amplitude of $6 \%$ ). 


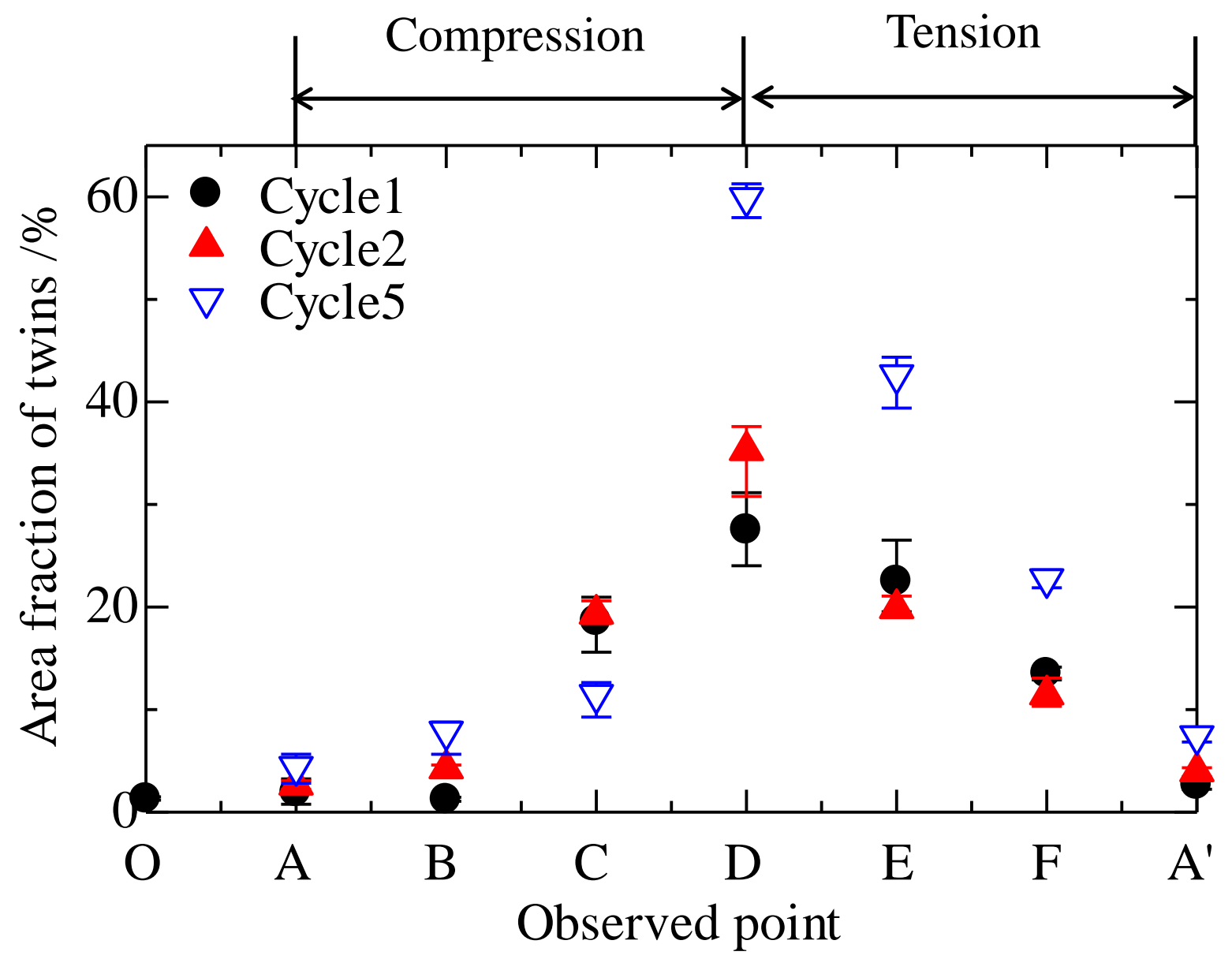

(a) Area fraction of twins at all observed points during cycles1, 2, and 5. 


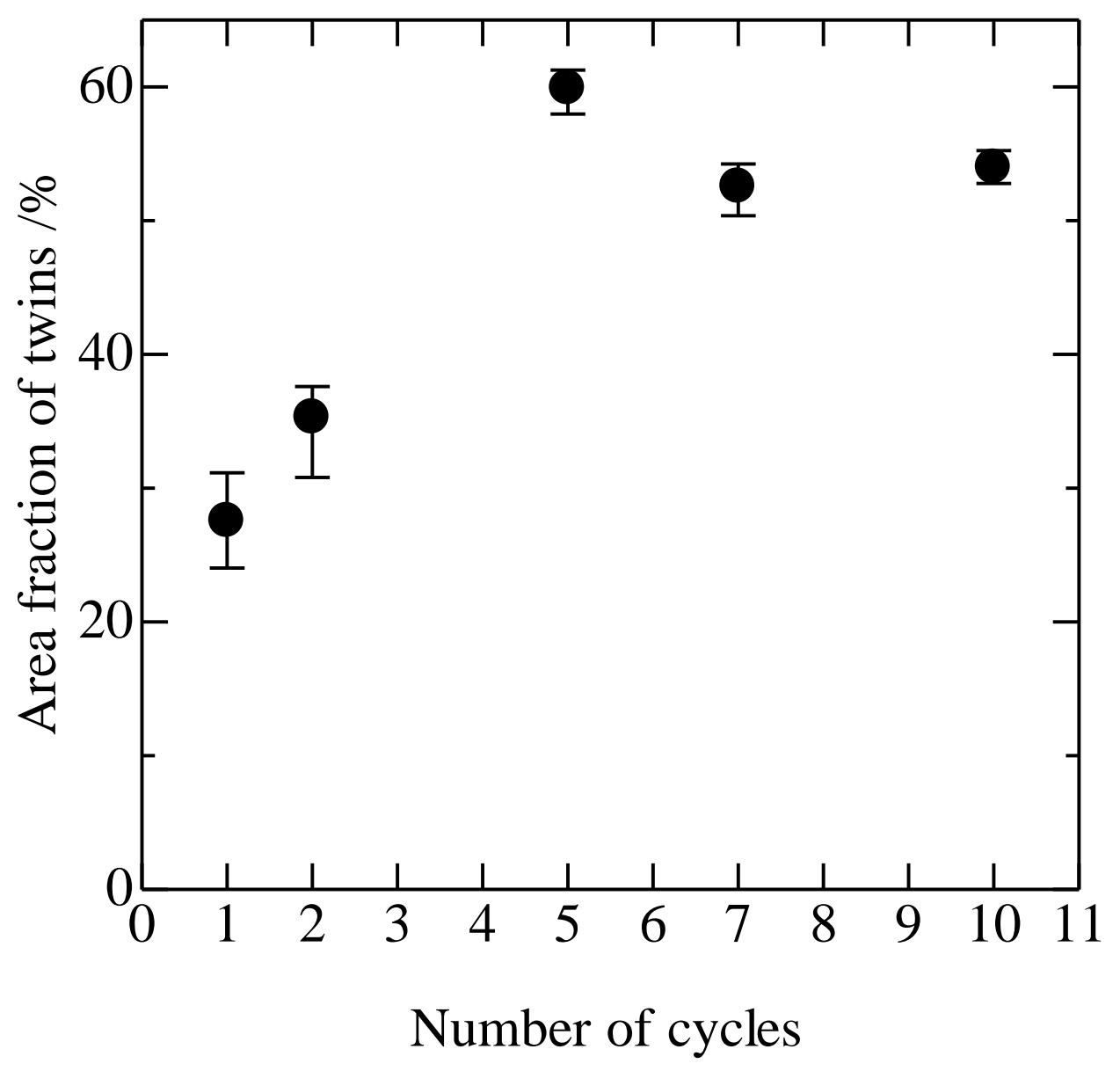

(b) Changes in area fraction of twins at point $\mathrm{D}$ as a function of the number of cycles.

Fig. 7 Changes in area fraction of twins. 


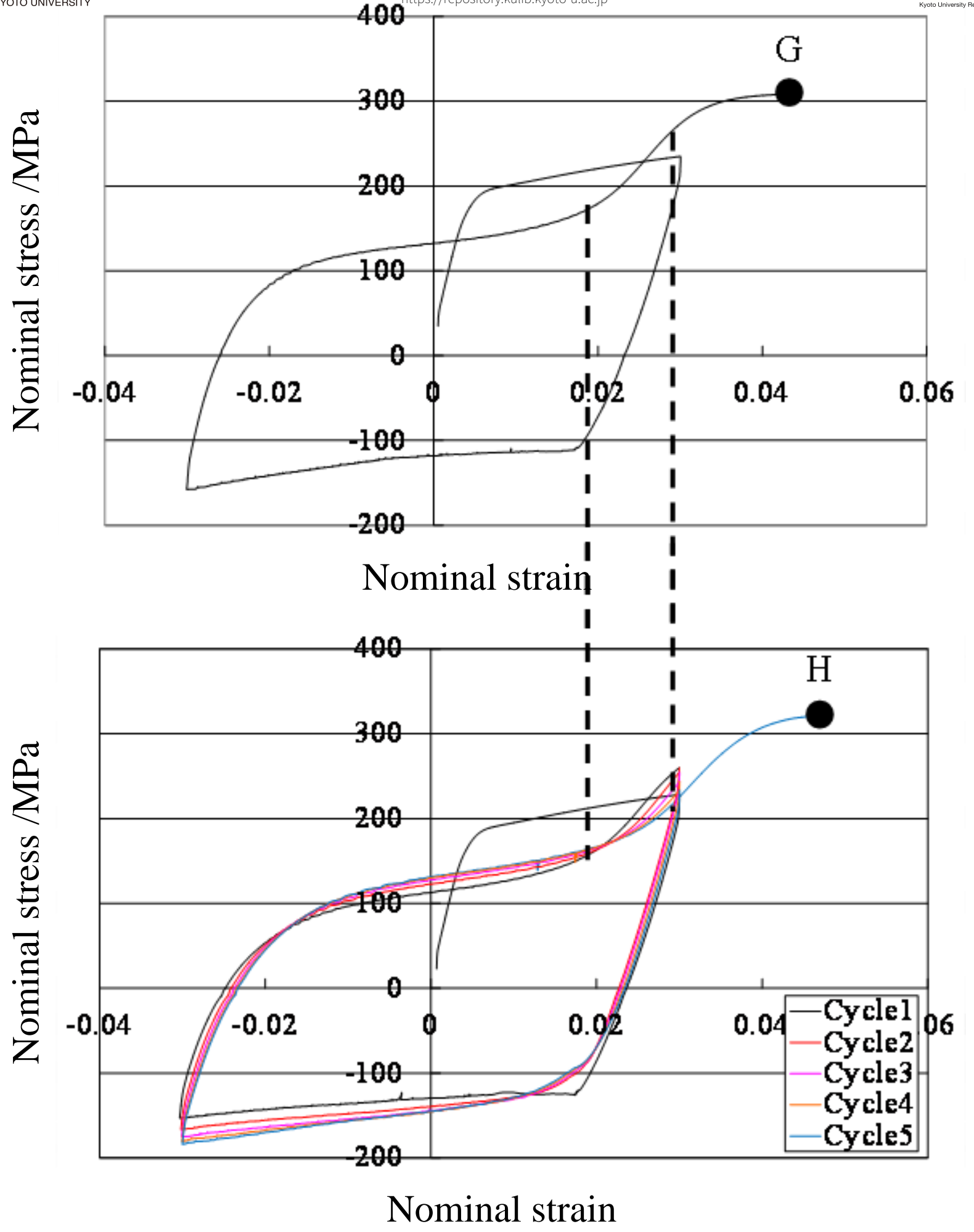

(a) Stress-strain curves. 


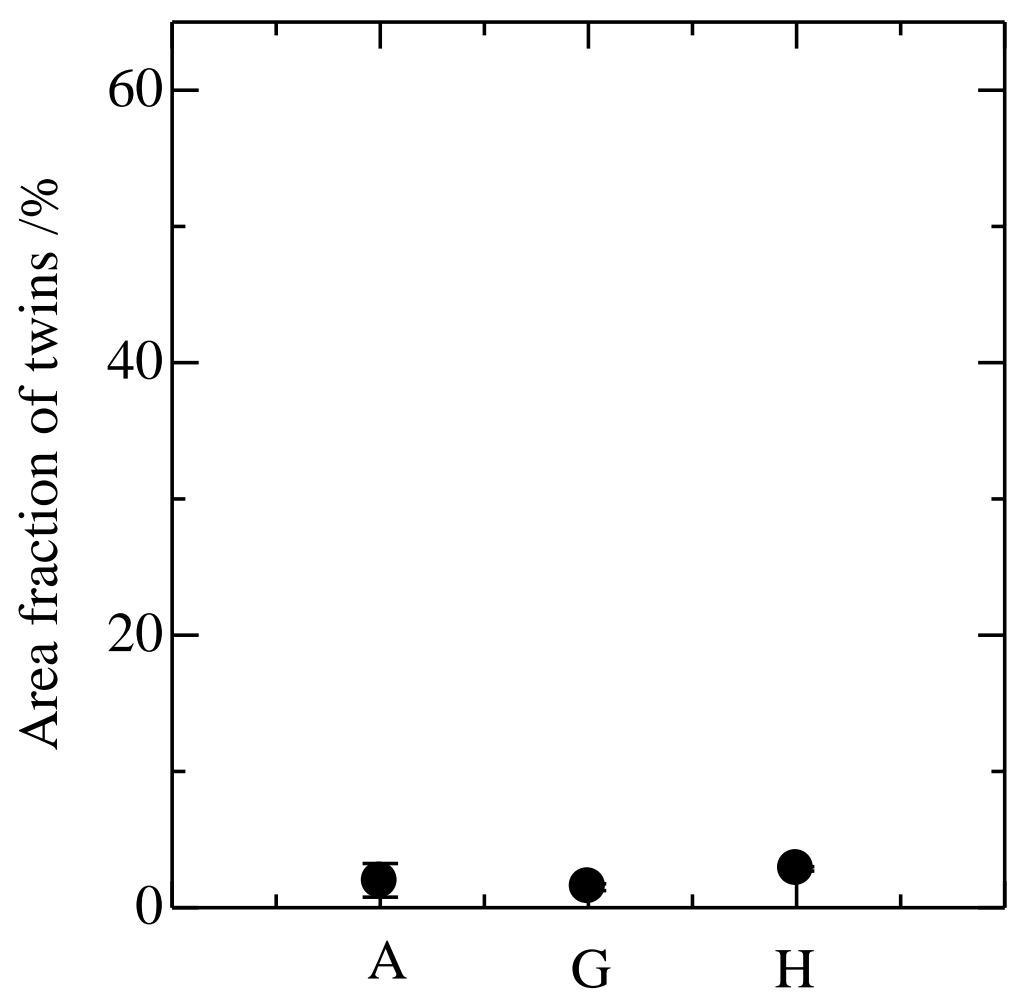

Observed point

(b) Area fraction of twins.

Fig. 8 Results obtained by one and five cyclic loadings followed by tension. 


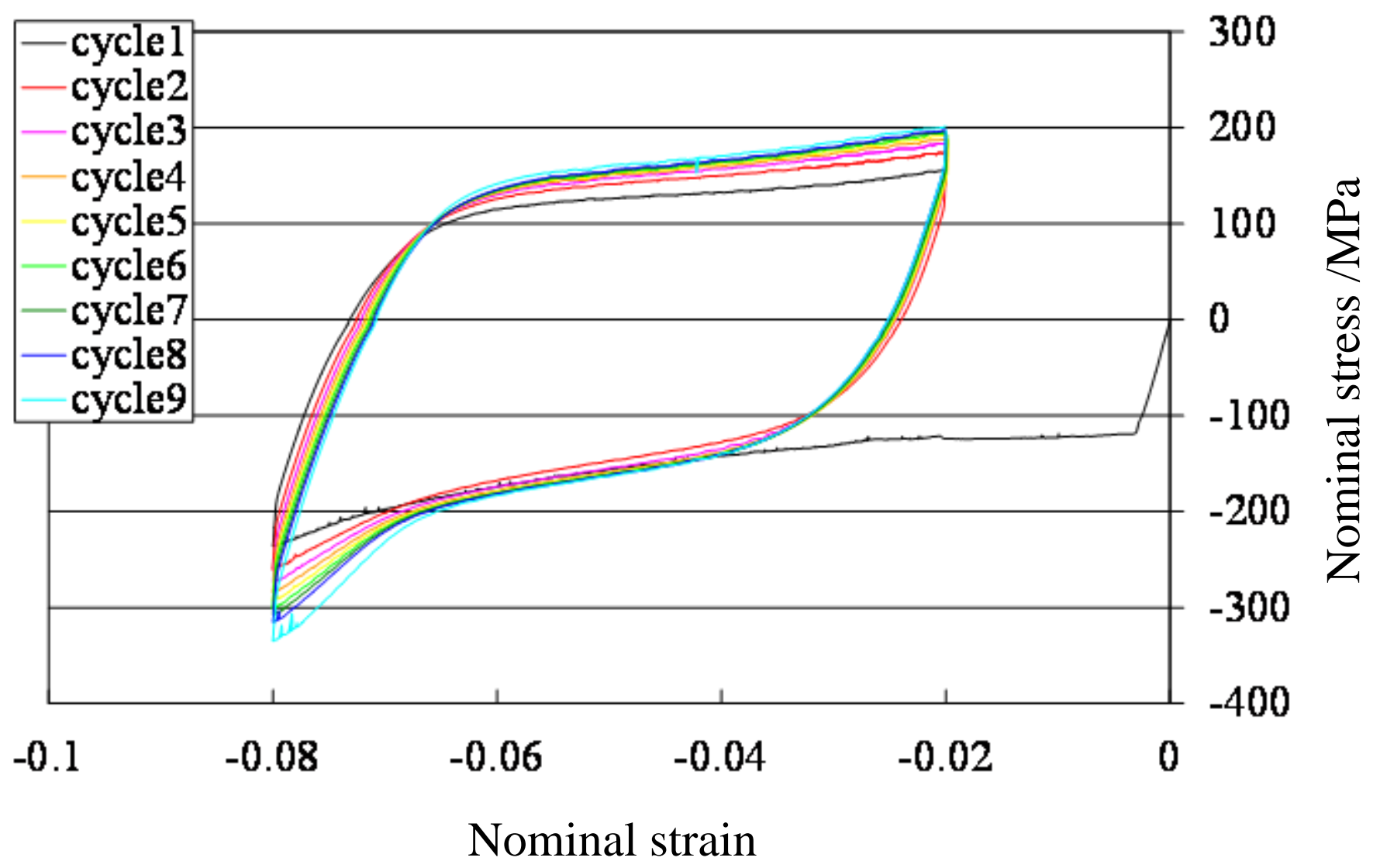

Fig. 9 Stress-strain curve obtained by cyclic loading tests after compressive strains were applied with a strain amplitude of $6 \%$. 


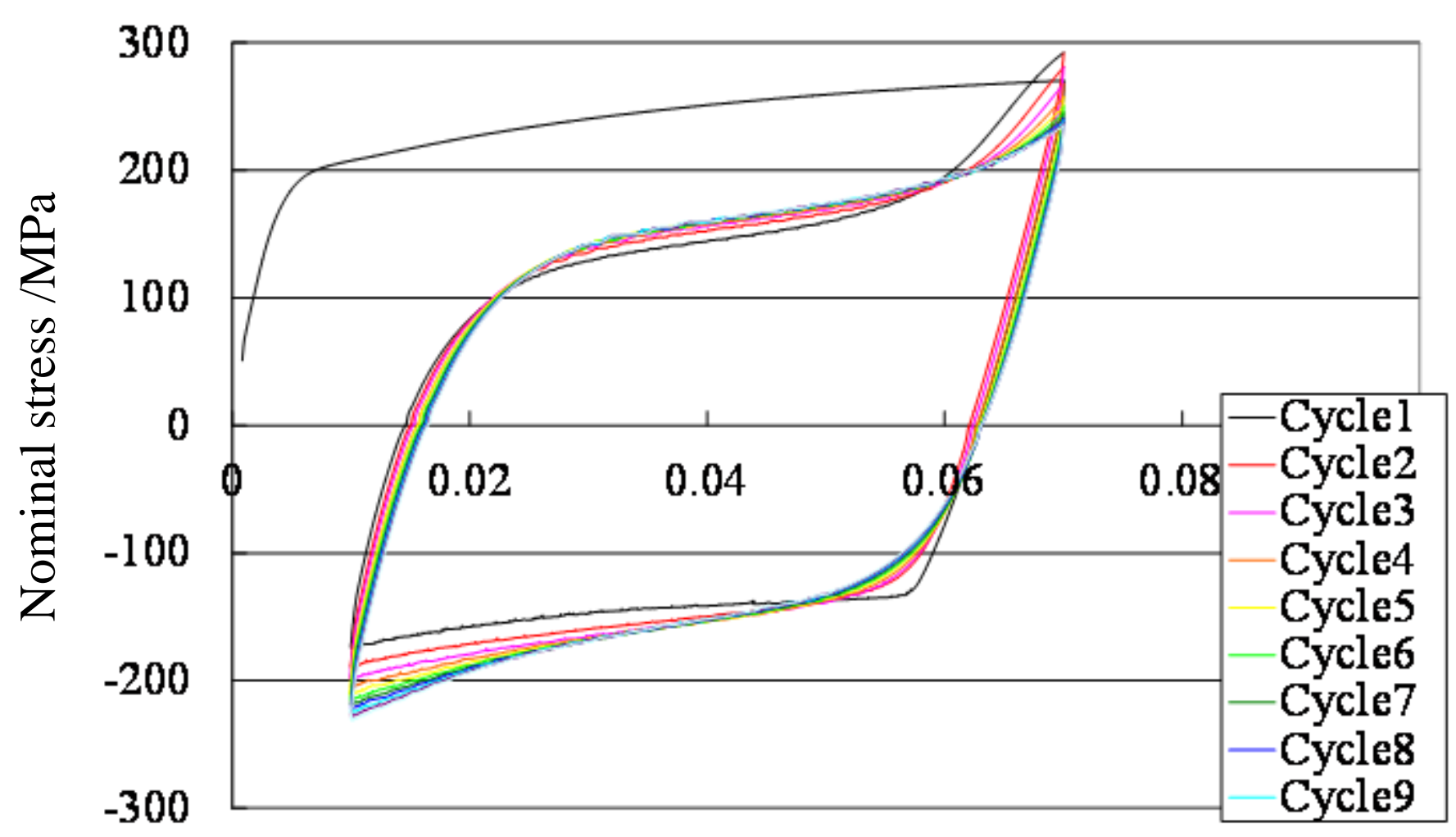

Nominal strain

Fig. 10 Stress-strain curve obtained by cyclic loading test after tensile strain was applied with a strain amplitude of $6 \%$. 
Table 1. Mechanical properties of sheet obtained by monotonic tension test.* 
Table 1. Mechanical properties of sheet obtained by monotonic tension test.*

\begin{tabular}{ccccccc}
\hline$E / \mathrm{GPa}$ & $\sigma_{0.2} / \mathrm{MPa}$ & $\sigma_{T} / \mathrm{MPa}$ & $r_{10 \%}$ & $r_{15 \%}$ & $F / \mathrm{MPa}$ & $n$ \\
\hline 40 & 168 & 264 & 2.25 & 2.79 & 478 & 0.225 \\
\hline
\end{tabular}

* The true stress-strain curve is approximated with $\sigma=F \varepsilon^{n}$. 